\title{
Coal-biomass mixing characteristics in a bubbling fluidized bed of Geldart A particles
}

\author{
Bahareh Estejab ${ }^{*}$, Guevara Che Nyendu ${ }^{\dagger}$, Foster Agblevor $^{\dagger}$, Francine Battaglia ${ }^{*}$ \\ *Mechanical Engineering Department, Virginia Polytechnic Institute and State University, \\ Blacksburg, Virginia 24061 \\ ${ }^{\dagger}$ USTAR Bioenergy Center, Biological Engineering Department, Utah State University, \\ Logan, Utah 84322
}

\begin{abstract}
In an effort to assess fluidization of coal-biomass mixtures, experiments and numerical simulations were used to better understand the dynamics in terms of mixing and bed characteristics. The computational platform MFiX was employed to simulate the particle-particle interactions of coal-biomass mixtures and compare the predictions with experimental data. The mixtures included sub-bituminous coal and hybrid poplar wood, which both are classified as Geldart A particles. Three mass ratio mixtures of 90:10, 80:20, and 70:30 coal:poplar wood were studied, and pressure drop and bed height for various gas inlet velocities were analyzed and compared to the experiments, which were in good agreement. It was found that the bed with $10 \%$ poplar wood showed characteristics consistent with a bed of coal and the bed with only $30 \%$ poplar wood was similar to a bed of poplar wood. A quantitative analysis of the mixing index confirmed that as the poplar wood mass ratio increased, the quality of mixing improved, with an average mixing index of $62 \%$. Therefore, reasonable amounts of biomass can be added with coal without adverse effects of segregation or elutriation.
\end{abstract}

Keywords: biomass; binary mixtures; coal; fluidization; Geldart A particles; mixing

Corresponding author: Phone: 540-231-0077; Fax: 540-231-9100; Email: fbattaglia@vt.edu 


\section{Introduction}

Coal is a common source of energy, which supplies more than $50 \%$ of the Nation's energy needs and continues to be a more viable option due to rising oil and natural gas prices (Baskara Sethupathy and Natarajan, 2012; Department of Energy, 2008); however, the undesired pollution and carbon emission levels have been a problem (House of Representatives, 2010). Biomass is being considered as a renewable energy resource, and includes a wide range of materials. The issue is that while biomass is environmentally friendly, it cannot be easily used in existing gasifiers without incurring increased costs in retrofits. Furthermore, gasification of biomass alone is not economically efficient or cost-effective because of its lower calorific value and density compared to fuels like coal (Prins et al., 2007). Coal-biomass fuel mixtures have great potential to provide cleaner, low-cost, domestic energy (Cuellar, 2012). However, understanding of the nature of coal-biomass gasification is not possible without adequate independent knowledge of coal and biomass fluidization.

The main focus of this study is to numerically investigate Geldart A particles that have small diameters $(20-100 \mu \mathrm{m})$ and/or low densities $\left(<1.4 \mathrm{~g} / \mathrm{cm}^{3}\right)$. At low inlet gas velocities, the bed of particles expands significantly prior to fluidization. Once a critical velocity is attained, bubbles commence after which the particles fluidize easily and the bubble rising velocity is much higher than the gas inlet velocity (Geldart, 1973). In contrast, beds of Geldart B particles form bubbles at or after the inception of fluidization but the bed expansion is small. Our study examines fluidization of coal and hybrid poplar wood materials. Notwithstanding the fact that numerous experimental studies on the fluidization of Geldart A particles have been conducted (Lettieri et al., 2002; Rapagna et al., 1994; Sidorenko and Rhodes, 2004; Simone and Harriott, 1980; Xie and Geldart, 1995) and numerical studies on fluid catalytic cracking (FCC) particles that are 
classified as Geldart A have been reported (Benyahia et al., 2000; Gao et al., 2009; Han and Chung, 2001; Jiradilok et al., 2006; McKeen and Pugsley, 2003), a thorough understanding of fluidization hydrodynamics of Geldart A still lacks.

To the best of our knowledge, so far there have been no published numerical studies specific to Geldart A biomass or coal particles and their fluidization as a mixture, and thus provide the motivation for the numerical study herein. However, different hydrodynamic Lagrangian models have been proposed by researchers to model fine particles. Here, only a few that focused on the existence of an overshoot of pressure drop in Geldart A fluidization are discussed. One of the early models developed by Anderson and Jackson (1967) was a one-dimensional DPM model, which used local mean variables for fluid velocity and pressure, and solids velocities were introduced. Later the model was employed by Jackson $(1998,2000)$ to show the effect of wall friction on fluidization behavior, especially, pressure drop overshoot for non-cohesive materials. Srivastava and Sundaresan (2002) found that the model proposed by Anderson and Jackson (1967) was able to capture the fluidization behavior of fine particles in restricted conditions for a first order compressive yield stress equation. Loezos et al. (2002) used an improved version of the Anderson and Jackson model (1967) and proposed that not only wall friction but also compressive yield stress of the particles can have dramatic effects on all fluidizationdefluidization characteristics including the pressure drop spike. Loezos et al. (2002) confirmed their results with Ye et al. (2005) who used a 3D DPM model and proposed that fluidization behavior of fine particles is also influenced by inter-particles Van der Waals forces. However, the effect of wall friction on pressure drop was shown to be negligible by Reddy and Joshi (2010).

Eulerian models have shown some deficiencies in predicting Geldart A fluidization behavior (Ferschneider and Mege, 1996; Krishna and Van Baten, 2001; Van Wachem et al., 2001). To 
improve two-fluid models to capture fine particle fluidization behavior, many attempts have been made (Wang, 2009). Studies have reported the existence of particle clusters in the gas-solids flow (Harris et al., 2002; Lackermeier et al., 2001; Mostoufi and Chaouki, 2004), which are the result of inter-particles forces that are specifically important for Geldart A particles. In an effort to improve prediction of Geldart A particle fluidization using two-fluid models, some models (Huilin et al., 2005; Shuyan et al., 2008) based on the cluster movement of particles (clusterbased approach) were proposed that were in a good agreement with experiments. The main difficulty in these models was to correctly predict the size of clusters for different applications of the models. To eliminate this complication, some researchers tried to use the traditional particlebased approach and modified the drag models to capture the importance of particle clusters in Geldart A fluidization behavior (McKeen and Pugsley, 2003; Ye et al., 2004; Ye et al., 2008).

McKeen and Pugsley (2003) used the computational fluid dynamics (CFD) code, Multiphase Flow with Interphase eXchanges (MFiX), to study freely bubbling FCC beds and compared the simulations to experiments. Employing common drag models for fine particles, McKeen and Pugsley (2003) reported severely over-predicted bed expansions and proposed that commonlyused models for coarser particles only with modification on gas-solids drag closure law can be employed to correctly predict the Geldart A particles fluidization behavior. They tried to solve the problem by using a modified drag law corresponding to a larger particle diameter by applying a scale factor of 0.2 to 0.3 , which leads to smaller drag forces acting on the particles. McKeen \& Pugsley (2003) claimed that their finding was in accordance with significant cohesive inter-particle forces of fine particles. Similarly, Ye et al. (2004; 2008) emphasized inter-particles forces and suggested to modify drag models to correctly predict the hydrodynamic behavior of Geldart A particles using the two-fluid model. Ye et al. (2008) suggested that the 
drag model must be scaled-down at low gas velocities and scaled-up at high gas velocities and proposed that the scale factors account for the contribution of cohesion to the excess compressibility of fine particles.

In contrast with these groups of researchers who artificially modified the two-fluid models, Parmentier et al. (2008) investigated the influence of mesh size on fluidization behavior of particles and found a drastic improvement of the bed height predictions with sufficiently small cell sizes with no need to modify the model or drag law. Parmentier et al. (2008) also proposed an empirical law to find grid mesh size to ensure mesh independent results. Wang et al. (2009; 2010) also emphasized the necessity of sufficiently fine grid size and small time step to correctly predict the fluidization behavior of Geldart A particles using two-fluid models. However, with current and foreseeable computer resources, their methods (Parmentier et al. (2008), Wang et al. $(2009 ; 2010))$ are very computationally intensive, if even feasible for a large-scale dense fluidized bed systems.

Other studies have documented that the inherently heterogeneous nature of a bubbling bed of Geldart A particles and the presence of particle clusters over a wide range of length and time scales was responsible for the failure of two-fluid models in capturing fluidization behavior of fine particles. This group of researchers tried to employ new drag models to count for these structures. Wang (2009) emphasized the necessity of a suitable subgrid-scale (SGS) model to deem the effect of meso-scale structures for successfully describing the hydrodynamics of a fluidized bed containing Geldart A particles. Lu et al. (2011) also concentrated on the meso-scale structures that significantly affect Geldart A particle performance and proposed that even very fine grids are not capable of capturing these structures. In contrast, Lu et al. (2011) suggested 
that using an energy-minimization multi-scale (EMMS) drag model can correctly predict fluidization behavior. Benzarti et al. (2012), as well, reported good performance of an EMMS drag model in predicting the bed expansion of Geldart A particles. However, these models are mathematically conflicted because they represent the heterogeneous nature of the flow yet are coupled to models for kinetic theory for granular flow, which is based on homogeneous fluidization.

Despite the aforementioned studies that attempt to correctly predict the fluidization behavior of Geldart A particles, there has not been a method that has truly prevailed. A summary of all studies discussed here that employed Eulerian models is presented in Table 1. The goal of the current research is to use experiments and two-fluid model simulations to analyze the hydrodynamics of coal-biomass fluidized beds of Geldart A particles considering the dead zones in the bed that do not contribute in the fluidization. In this study, particle mixing behavior is also investigated. Particle properties in a fluidized bed have a strong impact on solids mixing behavior, which must be considered carefully to understand fluidization. Due to differences in particle properties in a binary bed, the mixing behavior is expected to be more complicated than a single-solid fluidized bed. Using Eulerian-Eulerian models to study mixing behavior will be a big step forward toward minimizing the scale up problems when modeling larger reactors. Simulations will be employed using MFiX with a combination of the Ergun and Wen \& Yu correlations (Gidaspow, 1994; Syamlal et al., 1993) to calculate the inter-phase drag force. Predictions of pressure drop and bed height are compared and validated with experiments for sub-bituminous coal and hybrid poplar wood particles, which are both classified as Geldart A. To study particle mixing, gas and solids volume fractions, mass flux and particle velocities are examined, and the mixing index is reported. 


\section{Experimental Setup and procedure}

\subsection{Fluidized bed reactor}

The fluidized bed reactor used in the experiments is made from borosilicate glass and equipped with a $100-\mu \mathrm{m}$ frit gas distributor. The reactor has a $5.08 \mathrm{~cm}$ inner diameter and $30 \mathrm{~cm}$ height. At the top of the reactor column, an expanding freeboard zone is provided to reduce particle entrainment. Figure 1(a) shows a schematic diagram of a 2D plane of the reactor height. The experimental set-up consists of three main units: nitrogen source (1), fluidizing reactor (8), and a U-tube manometer filled with distilled water (11). Nitrogen gas is fed into the reactor from the base of the distributor plate and the reactor discharged to the atmosphere. Two materials are considered to study the minimum fluidization velocity, pressure drop and bed expansion trends: coal, poplar, and coal-poplar mixtures. The properties for each material are shown in Table 2. All experiments are performed at room temperature and atmospheric pressure.

To begin, the pressure drop across the gas distributor was first determined at all flow rates when the reactor was empty. The value is used to correct pressure drop measurements for the reactor with particles. Then, test materials were loaded into the fluidization column to create a packed bed and the initial height of the bed was recorded. Following this step, nitrogen was injected below the distributor plate incrementally from zero and progressively at a rate of 33 $\mathrm{cm}^{3} / \mathrm{s}$ to $233 \mathrm{~cm}^{3} / \mathrm{s}$, which corresponds to $11.5 \mathrm{~cm} / \mathrm{s}$. The procedure utilized an Aalborg mass flow controller (Model GFC 37, Orangeburg, New York,) with a range of 0-500 $\mathrm{cm}^{3} / \mathrm{s}$ and accuracy $\pm 1.5 \%$. The pressure drop was measured by a distilled water filled manometer (accuracy of \pm 0.25 ) and was recorded when the bed reached a stable state at each flow rate. The initial and final bed heights were recorded and visual observations were made. Each fluidization experiment was repeated three times using the same procedure. The fluidization experiments 
were also conducted by starting with a fully fluidized bed and reducing the flow rates to determine if the pressure drop characteristics were the same. Overall, the same minimum fluidization and bubbling velocities were measured. Therefore, data will be presented for forward fluidization.

\subsection{Bed porosity at minimum fluidization velocity}

To calculate the bed porosity at minimum fluidization, the bed heights corresponding to minimum fluidization velocity were measured. The average bed porosity $\left(\varepsilon_{m f}\right)$ was estimated using

$$
\varepsilon_{m f}=1-\left(m_{s} / \rho_{s} h_{0} A\right)
$$

where $m_{s}$ is the particle mass, $\rho_{s}$ is the particle density, $h_{0}$ is the bed height at minimum fluidization, and $A$ is the cross-sectional area of the reactor column normal to the incoming flow. The particle densities of coal and hybrid poplar wood mixtures were calculated as the sum of individual test materials based on the mass fraction $X_{i}$ and material density $\rho_{i}$ using the definition of mixture mean density:

$$
\bar{\rho}_{m i x}=\left|\sum_{i=1}^{M}\left(X_{i} / \rho_{i}\right)\right|^{-1}
$$

\subsection{Particle density and size analysis}

The bulk densities of coal and poplar wood materials were calculated using the ratio of mass and the volume occupied by the material. Samples were gently poured into a measuring cylinder and allowed to settle freely. The mass and volume of sample were measured and the bulk density calculated. To calculate particles densities of materials, the ratio of mass per unit volume of solid particles was used. Coal particle density was determined using methanol. 
Particles size distributions were determined using Ro-Tap® Model E test sieve shaker (W. S. Tyler, Mentor, $\mathrm{OH})$. Ten sieves with size ranges from $850 \mu \mathrm{m}$ to $45 \mu \mathrm{m}$ were used for the analysis. After sieving, the materials retained on each sieve were weighed and recorded and the particle mean diameter was determined. The particle size distributions for coal and poplar wood are presented in Figures 2 and 3, respectively. Further experimental details can be found in (Nyendu, 2015).

\section{Numerical formulation}

\subsection{Governing equations}

In the present study, the code Multiphase Flow with Interphase eXchanges (MFiX) is employed for all simulations (Syamlal et al., 1993). The gas and solids phases are modeled using an Eulerian-Eulerian approach to efficiently simulate the physics during fluidization and has been used extensively by Battaglia e.g., (Deza and Battaglia, 2013; Sun and Battaglia, 2006; Xie et al., 2008). Each phase behaves as interpenetrating continua that has its own physical properties. In order to derive equations that describe the phase interaction, the instantaneous variables are averaged over a region that is larger than the particle spacing but smaller than the flow domain.

To track the volume occupied by each phase, volume fractions are introduced where $\varepsilon_{g}$ is the gas volume fraction (void fraction) and $\varepsilon_{s}$ is the solids volume fraction. The volume fractions must satisfy:

$$
\varepsilon_{g}+\sum_{m=1}^{M} \varepsilon_{s m}=1
$$

where $m$ is the solids component and $M$ is the total number of solids phases in the system. Continuity equations are solved for the gas phase and solids phases, respectively, are: 


$$
\begin{gathered}
\frac{\partial}{\partial t}\left(\varepsilon_{g} \rho_{g}\right)+\nabla \cdot\left(\varepsilon_{g} \rho_{g} \vec{u}_{g}\right)=0 \\
\frac{\partial}{\partial t}\left(\varepsilon_{s m} \rho_{s m}\right)+\nabla \cdot\left(\varepsilon_{s m} \rho_{s m} \vec{u}_{s m}\right)=0
\end{gathered}
$$

where $\rho$ is density and $\vec{u}$ is velocity vector. Gas density can be modeled using the ideal gas law:

$$
\rho_{g}=p_{g} M W / R T_{g}
$$

where $p_{g}$ is the gas pressure, $M W$ is the gas molecular weight, $R$ is the universal gas constant and $T_{g}$ is the gas temperature.

The momentum equations for the gas phase and $m^{\text {th }}$ solids phase, respectively, are:

$$
\begin{gathered}
\frac{\partial}{\partial t}\left(\varepsilon_{g} \rho_{g} \vec{u}_{g}\right)+\nabla \cdot\left(\varepsilon_{g} \rho_{g} \vec{u}_{g} \vec{u}_{g}\right)=-\varepsilon_{g} \nabla p_{g}+\nabla \cdot \overline{\bar{\tau}}_{g}+\sum_{m=1}^{M} F_{g}\left(\vec{u}_{s m}-\vec{u}_{g}\right)+\varepsilon_{g} \rho_{g} \vec{g} \\
\frac{\partial}{\partial t}\left(\varepsilon_{s m} \rho_{s m} \vec{u}_{s m}\right)+\nabla \cdot\left(\varepsilon_{s m} \rho_{s m} \vec{u}_{s m} \vec{u}_{s m}\right)=-\varepsilon_{s m} \nabla p_{g}+\nabla \cdot \overline{\bar{\sigma}}_{s m}-F_{g}\left(\vec{u}_{s m}-\vec{u}_{g}\right)+\varepsilon_{s m} \rho_{s m} \vec{g}+\sum_{\substack{l=1 \\
l \neq m}}^{M} \vec{I}_{m l}
\end{gathered}
$$

The terms on the left hand side represent the rate of momentum increase and net rate of momentum transfer by advection, respectively. Terms on the right hand side represent contributions of buoyancy caused by the fluid pressure gradient, the viscous stress tensor $\overline{\bar{\tau}}_{g}$ in Eq. (8), the solids phase stress tensor $\overline{\bar{\sigma}}_{s m}$ (which is a summation of the pressure and viscous stress tensors) in Eq. (9) and, gas and solids phases interaction, and gravity. The last term in Eq. (9) is the particle interaction force between the $m^{\text {th }}$ and $l^{\text {th }}$ solids phases. In order to find the drag coefficient to calculate the solids-solids momentum transfer, a simplified version of kinetic theory for granular flow proposed by Syamlal (1987) is used.

The gas-solids momentum transfer in Eqs. (8) and (9) is expressed as a drag force and is defined as the product of $F_{g}$ that is the coefficient of interphase drag force between the gas and the solids phases and the slip velocity between the phases, $\left(\vec{u}_{s m}-\vec{u}_{g}\right)$. To develop a relation for 
$F_{g}$, many experimental methods have been proposed (Gidaspow, 1994; Syamlal et al., 1993). In this study, the Gidaspow model is employed and the accuracy of using this model to predict Geldart A fluidization was confirmed by Estejab and Battaglia (2016). To calculate the interphase drag force coefficient, the Gidaspow model uses two correlations depending on the local void fraction coupled with blending function (Huilin and Gidaspow, 2003) when switching between correlations (Lathouwers and Bellan, 2000).

The granular temperature $\theta$ for the solids phase is proportional to the granular energy defined as the specific kinetic energy of the random fluctuating component of the particle velocity. In rapid granular flow, the kinetic energy of random particle fluctuations is derived from the kinetic energy of the mean flow (Syamlal, 1998; Syamlal et al., 1993). It should also be noted that the solids stress tensor $\overline{\bar{\sigma}}_{s m}$ shown in Eq. (9) is defined in terms of a plastic regime and a viscous regime, where the viscous regime is a function of $\theta$. Further details of the constituent relationships can be found in (Syamlal et al., 1993).

The resulting transport of granular energy for the $m^{\text {th }}$ solids phase is:

$$
\frac{3}{2}\left[\frac{\partial}{\partial t}\left(\varepsilon_{s m} \rho_{s m} \theta_{m}\right)+\nabla \cdot\left(\varepsilon_{s m} \rho_{s m} \theta\right) \vec{u}_{s m}\right]=\overline{\bar{\sigma}}_{s m}: \nabla \vec{u}_{s m}-\nabla \cdot \vec{q}_{\theta}-\gamma_{\theta}+\phi_{g m}+\sum_{\substack{l=1 \\ l \neq m}}^{M} \phi_{m l}
$$

where $q_{\theta}$ is the diffusive flux of granular energy, $\gamma_{\theta}$ is the rate of granular energy dissipation due to inelastic collision, and $\phi_{g m}$ is the transfer of granular energy between the gas phase and the $m^{\text {th }}$ solids phase.

To reduce numerical instabilities, the governing equations are discretized using a finite volume approach for staggered grids. Discretization of temporal and spatial derivatives are firstorder and second-order, respectively. To improve the convergence and accuracy of the solution, 
the convection terms are discretized using the Superbee method (Syamlal, 1997). To solve the governing equations, MFiX uses a modification of Semi Implicit Method for Pressure Linked Equations (SIMPLE) algorithm proposed by Patankar (1980), which is the most widely used primitive-variable method. The first modification replaces the solids pressure correction equation with a solids volume fraction correction equation, which incorporates the effect of the solids pressure and helps to stabilize and facilitate convergence of both loosely and densely packed regions. To increase the execution speeds, a second modification introduces a variable timestepping scheme. The number of iterations per time step is monitored, and if convergence occurs in less than the maximum number of iterations, the time step is doubled. If convergence is not satisfied, the time step is halved and the calculation is repeated. The process continues until convergence is satisfied (Syamlal, 1998).

\subsection{Problem description}

The cylindrical reactor is modeled in a Cartesian coordinate system as a 2D plane representing the center-plane of the cylinder, illustrated in Figure 1(b). The gas inlet velocity at the bottom of the reactor, i.e., the inlet of distributor plate, is defined as a uniform velocity and atmospheric pressure is specified at the exit. To model the gas-wall and particle-wall interactions, no-slip and partial-slip boundary conditions are used, respectively.

The grid resolution study is performed for the pressure drop of a single-component system of poplar wood for gas inlet velocity $U_{g}=8.22 \mathrm{~cm} / \mathrm{s}$ using the geometry that is presented in Figure 1(b). The rectangular domain is discretized uniformly using a coarse mesh $(20 \times 100)$, medium mesh $(40 \times 200)$, and fine mesh $(80 \times 400)$. The cell sizes along with the central processing unit time are shown in Table 3. The numerical uncertainty due to discretization is estimated by analyzing the grid convergence index (GCI) (Celik et al., 2008). The GCI values for the 
predicted pressure drop for poplar wood are 3\% and 1\% changing from coarse to medium mesh and medium to fine mesh (Estejab and Battaglia, 2016). Since the medium mesh is less computationally expensive compared to the fine mesh, the medium mesh will be used for the following cases.

\section{Results and discussion}

\subsection{Coal and poplar wood fluidization}

Geldart A particles display an interval of homogeneous fluidization (non-bubbling expansion) before the onset of bubbling fluidization. The presence of the non-bubbling expansion zone for Geldart A particles is demonstrated by a spike in pressure after the minimum fluidization velocity $U_{m f}$. Such an overshoot of pressure drop has been reported by some researchers (Anderson and Jackson, 1967; Jackson, 1998, 2000; Ye et al., 2005). The critical velocity that demarcates the homogeneous and heterogeneous fluidization regimes is called the minimum bubbling velocity $U_{m b}$. Coal and poplar wood, whose properties are presented in Table 2, are used to investigate fluidization of Geldart A particles.

The analysis begins by comparing the predicted fluidization trends for coal and poplar with the experiments to determine how the materials behave individually before the binary solids mixture study. According to Kanholy et al. (2012), it was shown that a distributor plate does not always uniformly fluidize particles, creating static regions of particles between the distributor holes. They proposed a procedure to correct for the material that does not fluidize by adjusting the particle mass and initial volume fraction. The authors have used this procedure in previous studies of coal and poplar wood fluidization (Estejab and Battaglia, 2016) and have applied them here. Figure 4 ( $a$ and $b$ ) shows nondimensional pressure drop across the bed for the experiments and simulations for coal and poplar, respectively. The fluidization experiments for coal show an 
almost linearly increasing trend for pressure drop until the onset of fluidization close to $U_{m f}=1.6$ $\mathrm{cm} / \mathrm{s}$. Close to $U_{m f}$, a significant overshoot of pressure is observed for coal followed by a constant trend where $\Delta p=75 \mathrm{~Pa}$, which begins at $U_{m b}=6.6 \mathrm{~cm} / \mathrm{s}$ where the bed is fully fluidized. The simulations are similar to the experiments after $6.6 \mathrm{~cm} / \mathrm{s}$, when the bed is fully fluidized, after which the predicted pressure drop remains constant at $79 \mathrm{~Pa}$. The simulations for coal do not capture the spike in pressure drop, which could be due to the high level of inter-particle forces in this region. The effect of these forces is particle bridging that the model is unable to capture, and is not unlike previous studies (Harris et al., 2002; Lackermeier et al., 2001; Mostoufi and Chaouki, 2004). Furthermore, the coal particles are very fine and more uniformly distributed, creating larger inter-particle forces. As seen in the experiments, fewer gas channels form in the fluidized bed and the tight packing requires a larger force to overcome the interparticle forces before fluidization begins. However, if larger coal particles are used, the interparticle forces decrease because the rough particle edges create gaps through which the gas can flow through more easily; thus there will not be an increase in the pressure drop as observed here.

The fluidization experiments for poplar wood similarly show an almost linearly increasing trend until the commencement of fluidization at $U_{m f}=3.2 \mathrm{~cm} / \mathrm{s}$. There is a corresponding, albeit slight, overshoot of pressure near $U_{m f}$ followed by a constant value of $\Delta p=69 \mathrm{~Pa}$, which begins at $U_{m b}=8.2 \mathrm{~cm} / \mathrm{s}$. It was found that modeling the poplar wood was more challenging due to the irregular particle shapes. Based on the experimental observations of the poplar wood fluidization, it was noted that the particles would aggregate (i.e., particle bridging) forming clusters and gas flow channels. To represent the formation of particle clusters, the computational model was adjusted by increasing the particle diameter by a factor of two. Doing so produced very good 
results consistent with the experiments. Similar to coal, the simulations do not predict the overshoot of pressure drop near $U_{m f}$, however, the pressure in the fully fluidized region is predicted accurately at constant pressure of $71 \mathrm{~Pa}$.

The nondimensional bed height of coal and poplar wood versus gas inlet velocity are presented in Figure 5 ( $\mathrm{a}$ and $\mathrm{b}$ ) and compared to experiments. To compare the experimental and predicted bed height, a dimensionless parameter is defined that is the ratio of expanded bed height to the initial bed height. The simulations agree well with experiments, which confirm the validity of the simulation modeling. As velocity increases, the height of the particles expands, however, the bed height of coal increases more compared to poplar wood. The reason can be connected to the particle bridging that is prevalent during coal fluidization, which creates gas channels such that the displaced particles increase the bed height. Askaripour and Molaei Dehkordi (2015) claimed that particle size had a greater impact on bed expansion ratio.

The instantaneous void fraction contours based on the simulations for two gas inlet velocities, $U_{g}=4.93 \mathrm{~cm} / \mathrm{s}$ and $U_{g}=9.87 \mathrm{~cm} / \mathrm{s}$, are presented in Figure 6(a-b) and Figure 7(a-b) for coal and poplar wood, respectively. As the velocity increases, the size of the bubbles and the average bed height increases. Although for coal (Figure 6(a) and (b)) the bed is fluidized and bubbles formed for both velocities, simulations of poplar wood particles (Figure 7(a) and (b)) predict a weakly-fluidizing bed at the lower velocity. As the velocity increases, poplar wood fluidizes more readily and bubbles form. The time-averaged void fractions spatially averaged across the bed width versus the nondimensional height for the same two velocities for coal and poplar wood is shown in Figure 6(c) and 7(c), respectively. As velocity increases, the slope of the void fraction curve increases as more bubbles rise to the surface. These figures help to elucidate the amount of gas present in the bed, where there is more gas towards the particle-freeboard 
interface due to the presence of more bubbles. Figure 7(c) also reaffirms that the simulations predict the onset of heterogeneous fluidization after $4.93 \mathrm{~cm} / \mathrm{s}$. This is in accordance with our findings from pressure drop curves where the onset of the bubbling regime occurs at $U_{m b}=8.2$ $\mathrm{cm} / \mathrm{s}$. At the lower velocity, the mean void fraction has not changed significantly from the initial void fraction.

\subsection{Binary mixtures of coal and poplar fluidization}

Binary mixtures of coal-poplar are studied for mass ratios of 90:10, 80:20 and 70:30. In the experiments prior to fluidization, the samples were placed in a plastic one liter jar and mixed thoroughly before placed in the reactor. In the computational models, two solids phases are used to described each unique particle diameter and density, where $M=2$ in Eqs. 4-10. The initial condition is a mixed bed, consistent with the experiments, and prescribed with a void fraction, as adopted from Kanholy et al. (2012). Properties for the simulations for each solids phase and mass ratio are presented in Table 4. The nondimensional pressure drop across the bed for the simulations and experiments versus the gas inlet velocity for the three mass ratios are presented in Figure 8. The experiments show that pressure drop increases until the commencement of fluidization at $U_{m f}=2.7 \mathrm{~cm} / \mathrm{s}, 4.8 \mathrm{~cm} / \mathrm{s}$, and $4.5 \mathrm{~cm} / \mathrm{s}$ for mass ratios of 90:10, 80:20 and 70:30, respectively. This region is followed by a quite substantial pressure spike for the mass ratio of 90:10 and a slight overshoot of pressure for the 80:20 mass ratio. As the poplar wood mass ratio increases to $30 \%$, no overshoot of pressure is reported and the increasing region is trailed by a constant pressure drop at $114 \mathrm{~Pa}$. Similar to single solids phase predictions, simulations do not predict an overshoot of pressure drop for 90:10 and 80:20 mass ratios. The predicted pressure drops in the fully fluidized regimes remain constant at $87 \mathrm{~Pa}, 128 \mathrm{~Pa}$, and $117 \mathrm{~Pa}$ for mass ratios of 90:10, 80:20 and 70:30, respectively, which are very close to the experimental pressure drop. 
The pressure drop across the bed for all mixtures is higher than the single solids phases of coal or poplar (Figure 4). However, the pressure for the mass ratio of 90:10 is close to the single solids phase pressure. It is interesting to note that the value of $U_{m f}$ increases and then decreases with increasing mass ratio, however, $U_{m b}$ remains at approximately $8.2 \mathrm{~cm} / \mathrm{s}$ for the three cases. A plausible explanation for the changes in $U_{m f}$ is that the mixture ratio of 80:20 represents a transitional flow as more poplar wood is added to coal. The fine coal particles develop large inter-particle forces that sustain a more compact bed and restrict the gas flow. When 10\% poplar wood is added to the coal, the biomass reduces the coal particle forces and consequently reduces the bed packing because the biomass are irregular-shaped, fibrous particles that have large aspect ratios compared to the spherical coal particles. However, with the 90:10 mixture, there are not enough biomass particles to disrupt the tight packing formations of the coal. When the coal-tobiomass ratio increases to $80: 20$, there is enough biomass to disrupt the tight packing of coal particles and hence there is less pressure overshoot. As the biomass content increases to 70:30, the overshoot completely disappears, thus, the 80:20 appears to be a transition state. However, this observation is only true for poplar wood; for other biomass species, the ratio is different and suggests that the apparent transition state is function of the biomass species and biomass particle shape. Previous fluidization studies that used corn stover, pine, and switchgrass individually mixed with coal were observed to behave differently, whereby some of these biomass materials had lower transition state ratios and others had higher transition state ratios (Nyendu, 2015).

The nondimensional bed height for the three mixtures are presented in Figure $9(\mathrm{a}, \mathrm{b}$, and $\mathrm{c})$ and show that as the velocity increases, the average bed height expands for each mass ratio. The simulations are in good agreement with the experiments, although a higher bed height is predicted for the 90:10 mass ratio. It is important to note that the 90:10 mass ratio shows similar 
bed height trends as was seen in the single solids phase for coal fluidization (Figure 5(a)) with a sudden increase of bed height at medium velocities. As the poplar wood mass ratio increases to $30 \%$, the bed height trends are more similar to the single solids phase of poplar (Figure 5(b)), where bed height increases more uniformly. The bed height of the 80:20 mass ratio may be interpreted as a transitional state from a bed with properties consistent with coal to a bed with properties more similar to poplar. The sudden increase in bed height at the minimum fluidization velocity is still obvious for the $80: 20$ mass ratio, although less dramatic than the 90:10 mass ratio. It is also interesting to note that the bed height of the mixtures is higher than the bed height when poplar wood fluidized as a single solids phase but lower than the bed height when coal fluidized as a single solids phase (comparing Figures 5 and 9).

Figure 10 shows the time-averaged gas, coal and poplar wood volume fractions spatially averaged across the bed width versus the nondimensional height for $U_{g}=9.87 \mathrm{~cm} / \mathrm{s}$ for all mixture ratios. Similarly, as the poplar wood mass ratio increases from $10 \%$ to $30 \%$, the slope of the void fraction curve decreases and the bed height is lower. For the mass ratio of $80: 20$, the slope of the void fraction curve is very close to the slope of 70:30 mass ratio, which is consistent with bed height observations. Solid volume fractions show similar results. The 90:10 mass ratio has the highest fractions of coal at all heights; however, the coal volume fractions for 80:20 and 70:30 mass ratios have similar values in the vicinity of the freeboard near $Y / h_{0}=2.5$. Poplar wood volume fraction increases with increasing mass and is relatively constant throughout the bed, and can be connected to mixing characteristics, discussed next.

Mixing characteristics are an important feature that can induce better particle contact, which is essential for increasing the efficiency of the process. The fundamental mechanism of solids mixing is due to bubble movement in the bed during fluidization. In the close vicinity of bubbles 
that rise through the bed, solids are drawn into the wake of bubbles where mixing occurs due to the generated movement. In addition, rising bubbles carry a trail of particles upward and release them at the bed surface (freeboard) as they erupt. Particles then move downward in the region surrounding the bubbles. An overall circulation of particles in the axial direction of the bed ensues as the result of these phenomena. Meanwhile, in the lateral direction, sidewise motion of bubbles due to coalescence and interaction of adjacent bubbles and lateral dispersion of particles due to bubbles burst and result in lateral solids mixing (Nguyen et al., 1977; Woollard and Potter, 1968). Solids mixing quality improves as inlet gas velocity increases, which is due to intense internal circulation at higher gas velocities (Norouzi et al., 2011).

Solids mixing properties of a fluidized bed have been studied experimentally through tracing methods (Mostoufi and Chaouki, 2001; Norouzi et al., 2011; Stein et al., 2000), and numerically mostly through Lagrangian models (Glicksman et al., 2008; Liu et al., 2010; Rhodes et al., 2001). Mixing properties and quality of mixing are usually assessed through either establishing the exchange coefficient between the bubble wake and the emulsion phase or using the degree of particles mixing in the bed. A qualitative understanding of particle flow patterns can be acquired by studying snapshots of void fraction and solids volume fraction contours procured from simulations.

To quantify the mixing of particles in a fluidized bed, the mixing index $(M I)$ is one method that is used (Rowe, 1972). The mixing index is defined as:

$$
M I=\frac{X_{U}}{X_{T}} \times 100 \%
$$

where $X_{U}$ is the mass fraction of jetsam particles in the upper region of the bed and $X_{T}$ is the total mass fraction of the jetsam particles in the whole bed. Higher values of $M I$ represent better mixing of particles, whereby $M I=100 \%$ is a perfectly mixed bed and $M I=0$ is a completely 
segregated bed. In the context of this work, jetsam particles are the poplar wood particles because they tend to sink, versus the coal particles that tend to float (flotsam). Considering the upper region of the bed begins at $h / h_{0}=1$, the mixing index at $U_{g}=9.87 \mathrm{~cm} / \mathrm{s}$ for 90:10, 80:20, and 70:30 mass ratios is $60.69 \%, 61.92 \%$, and $64.12 \%$, respectively.

The instantaneous gas and solids volume fraction contours for coal and poplar wood at $t=30$ $\mathrm{s}$ for the three mass ratio mixtures are presented in Figure 11 for $U_{g}=9.87 \mathrm{~cm} / \mathrm{s}$. As the poplar wood mass ratio increases, void fraction contours (Figure 11(a)) show a more gas dilute bed, where there are regions of lower void fraction (corresponding to 0.6 that are medium blue) for the 70:30 mass ratio. The size of the bubbles (red regions in all figures) does not show any significant difference between each mass ratio. Instantaneous solids volume fraction contours (Figure 11(b-c)) show that the regions of higher concentration of coal and poplar wood are mostly coincident, which confirms suitable mixing for each mass ratio.

To further investigate particle mixing behavior at each mass ratio, the time-averaged solids axial and lateral mass flux and velocity vectors are presented. Axial mass flux of the solids spatially averaged across the bed radius versus the nondimensional height for $U_{g}=9.87 \mathrm{~cm} / \mathrm{s}$ for all mass ratios are presented in Figure 12(a). For the 90:10 mass ratio, mass flux is mostly positive and implies a dominant upward movement of solids particles. These results are consistent with observations during the experiments that particles are elutriating into the freeboard. The mass flow rate based on the integration of axial mass flux shows that as the poplar wood mass ratio increases, the particle mass flow rate increases, which leads to better axial mixing. The particle mass flow rates for the 90:10, 80:20, and 70:30 mass ratios are 50, 61, and $125 \mathrm{~g} / \mathrm{s}$, respectively. Figure 12(b) shows the lateral mass flux of the solids vertically averaged versus the radius of the reactor. Similar to the axial mass flux, as the poplar wood mass 
ratio increases, the lateral mass flux increases, which implies better lateral mixing of particles. Therefore, increasing the poplar wood mass ratio improves the mixing of particles.

The time-averaged coal velocity vectors and volume fraction contours for $U_{g}=9.87 \mathrm{~cm} / \mathrm{s}$ for all mass ratios are presented in Figure 13 (because of the similar vector pattern of coal and poplar wood, only coal velocity vectors are presented). For all mass ratios, the movement of particles creates regions of higher solids concentration in the vicinity of the walls, distributor plate and near the center of the bed; these regions are blue in the volume fraction contours. The movement of the particles for all mass ratios exhibits two similar vortices along the side walls near the distributor plate. For all mass ratios a portion of the particles create two separate vortices near the center of the bed in the vicinity of the freeboard. As the poplar mass ratio increases, the solids velocity pattern changes and the central vortical structure does not form. For 80:20 and 70:30 mass ratios, the velocity patterns are very similar. As poplar mass ratio increases, the particle velocities increase and facilitate better mixing characteristics for higher poplar mass ratios.

\section{Conclusions}

Numerical simulations and experiments of fluidized beds were used to better understand the fluidization and particle mixing behavior of coal-biomass mixtures. Coal and poplar wood that both fall into the Geldart A classification and three binary mixtures of coal and poplar wood for mass ratios of 90:10, 80:20 and 70:30 were studied and compared to the experiments. To simulate and analyze gas-solids hydrodynamic behavior of the fluidized bed, an EulerianEulerian model was used. The predictions for pressure drop across the bed and bed height were validated with the experiments and found to be in a good agreement. To investigate the mixing 
behavior of mixtures and complete the investigation, instantaneous void fraction contours, timeaveraged mass flux, velocity vectors and time-averaged void fractions were examined.

Pressure drop for the coal-poplar mixtures were higher than single solids phases for each material, however, the pressure of the 90:10 mass ratio was close to the single solids phase pressure drop. In the case of 90:10 coal-to-biomass ratio, fluidization did not improve because the addition of biomass did not significantly reduce the bed packing to overcome the strong interparticle forces. However, it was shown that there was less pressure drop overshoot compared to $100 \%$ coal particles. The observed experimental phenomenon of particle bridging was not readily captured in the CFD simulations because the model assumes a spherical particle, whereas a real particle is irregular and the rough particle surfaces sustain inter-particle forces.

It was found that the 90:10 mass ratio exhibited bed height trends similar with the single solids phase of coal, and as the poplar wood mass ratio increased to $30 \%$, the bed height trend was similar to the single solids phase of poplar wood. Although instantaneous solid volume fraction contours indicated good mixing characteristics for all mass ratio mixtures, solids mass flux and velocity vectors showed a tendency of better mixing for mixtures with higher poplar mass ratio. The mixing of coal and poplar wood was further examined to determine the effect on fluidization. A quantitative analysis of the mixing index confirmed that as the poplar wood mass ratio increased, the quality of mixing improved, with an average mixing index of $62 \%$. Therefore, reasonable amounts of biomass can be added with coal without adverse effects of segregation or elutriation, while reducing the use of a fossil fuel. 


\section{Acknowledgments}

The authors would like to thank the U.S. Department of Energy, contract number DE-FE0005476 for providing the financial support for this project, and a personal thanks to our program manager, Steven Markovich. The authors also acknowledge the Advanced Research Computing (http://www.arc.vt.edu) at Virginia Tech for providing computational resources and technical support that have contributed to the results reported within this paper.

\section{Nomenclature}

$\begin{array}{ll}a & \text { Projected area of a particle } \\ A & \text { Reactor cross-sectional area } \\ C_{D} & \text { Drag coefficient } \\ d & \text { Particle diameter } \\ \bar{d}_{p} & \text { Particle mean diameter } \\ F_{g} & \text { Coefficient of interphase drag force between the gas and the solids phases } \\ g & \text { Gravity } \\ h_{0} & \text { Reactor initial bed height } \\ h & \text { Reactor bed height } \\ \vec{I} & \text { Gas-solids momentum transfer } \\ m & \text { Mass } \\ m{ }^{\prime \prime} & \text { Mass Flux } \\ M & \text { Total number of solid phases } \\ M W & \text { Molecular weight } \\ p & \text { Pressure } \\ p r & \text { Perimeter of a particle } \\ q_{\theta} & \text { Diffusive flux of granular energy } \\ R & \text { Gas constant } \\ T & \text { Temperature } \\ \vec{u} & \text { Velocity } \\ U & \text { Velocity } \\ X & \text { Mass fraction }\end{array}$

\section{Greek Symbols}

$\begin{array}{ll}\gamma_{\theta} & \text { Rate of granular energy dissipation } \\ \varepsilon & \text { volume fraction } \\ \theta & \text { Granular temperature } \\ \mu & \text { Absolute viscosity }\end{array}$




$\begin{array}{ll}\rho & \text { Density } \\ \bar{\rho}_{\text {mix }} & \text { Mixture mean density } \\ \overline{\bar{\sigma}}_{s m} & \text { Solid phase stress tensor } \\ \overline{\bar{\tau}} & \text { Viscous stress tensor } \\ \phi & \text { Transfer of granular energy } \\ \psi & \text { Sphericity }\end{array}$

\section{Subscripts}

$\begin{array}{ll}\mathrm{b} & \text { Bulk } \\ i & \text { Component of a mixture } \\ \mathrm{g} & \text { Gas phase } \\ m, l & \text { Solids component indices } \\ \mathrm{mf} & \text { Minimum fluidization } \\ \mathrm{U} & \text { Upper region of bed } \\ \mathrm{s} & \text { Solids phase } \\ \mathrm{T} & \text { Total reactor }\end{array}$




\section{References}

Anderson, T.B., Jackson, R., 1967. Fluid Mechanical Description of Fluidized Beds. Equations of Motion. Industrial \& Engineering Chemistry Fundamentals 6, 527-539.

Askaripour, H., Molaei Dehkordi, A., 2015. Simulation of 3D freely bubbling gas-solid fluidized beds using various drag models: TFM approach. Chemical Engineering Research and Design 100, 377-390.

Baskara Sethupathy, S., Natarajan, E., 2012. Hydrodynamic study on gasification of biomass in a fluidized bed gasifier. Int J Eng Sci Technol 4, 316-323.

Benyahia, S., Arastoopour, H., Knowlton, T.M., Massah, H., 2000. Simulation of particles and gas flow behavior in the riser section of a circulating fluidized bed using the kinetic theory approach for the particulate phase. Powder Technology 112, 24-33.

Benzarti, S., Mhiri, H., Bournot, H., 2012. Drag models for Simulation Gas-Solid Flow in the Bubbling Fluidized Bed of FCC Particles. World Academy of Science, Engineering and Technology 61, 1138-1143.

Celik, I.B., Ghia, U., Roache, P.J., Freitas, C.J., Coleman, H., Raad, P.E., 2008. Procedure for Estimation and Reporting of Uncertainty Due to Discretization in CFD Applications. ASME Journal of Fluids Engineering 130, 078001.

Cuellar, A.D., 2012. Plant Power: The cost of using biomass for power generation and potential for decreased greenhouse gas emissions. Massachusetts Institute of Technology, Cambridge, MA.

Department of Energy, 2008. Annual Energy Outlook.

Deza, M., Battaglia, F., 2013. A CFD Study of Pressure Fluctuations to Determine Fluidization Regimes in Gas-Solid Beds. ASME Journal of Fluids Engineering 135, 101301.

Estejab, B., Battaglia, F., 2016. Assessment of Drag Models for Geldart A Particles in Bubbling Fluidized Beds. ASME Journal of Fluids Engineering 138, 031105.

Ferschneider, G., Mege, P., 1996. Eulerian simulation of dense phase fluidized beds. Oil \& Gas Science and Technology 51, 301-307.

Gao, J., Lan, X., Fan, Y., Chang, J., Wang, G., Lu, C., Xu, C., 2009. CFD modeling and validation of the turbulent fluidized bed of FCC particles. AIChE Journal 55, 1680-1694.

Geldart, D., 1973. Types of gas fluidization. Powder Technology 7, 285-292.

Gidaspow, D., 1994. Multiphase flow and fluidization: continuum and kinetic theory descriptions. Academic press. 
Glicksman, L., Carr, E., Noymer, P., 2008. Particle injection and mixing experiments in a onequarter scale model bubbling fluidized bed. Powder Technology 180, 284-288.

Han, I.-S., Chung, C.-B., 2001. Dynamic modeling and simulation of a fluidized catalytic cracking process. Part II: Property estimation and simulation. Chemical Engineering Science 56, 1973-1990.

Harris, A.T., Davidson, J.F., Thorpe, R.B., 2002. The prediction of particle cluster properties in the near wall region of a vertical riser (200157). Powder Technology 127, 128-143.

House of Representatives, 2010. Biomass for Thermal Energy and Electricity: A Research and Development Portfolio for the Future : Hearing Before the Subcommittee On Energy and Environment, Committee On Science and Technology. House of Representatives, One Hundred Eleventh Congress, First Session, October 21, 2009. Washington: U.S. G.P.O.

Huilin, L., Gidaspow, D., 2003. Hydrodynamics of binary fluidization in a riser: CFD simulation using two granular temperatures. Chemical Engineering Science 58, 3777-3792.

Huilin, L., Qiaoqun, S., Yurong, H., Yongli, S., Ding, J., Xiang, L., 2005. Numerical study of particle cluster flow in risers with cluster-based approach. Chemical Engineering Science 60, 6757-6767.

Jackson, R., 1998. The nature and role of effective stress in fluidized systems, 9th Fluidization Engineering Foundation Conference. Engineering Foundation, New York, pp. 1-14.

Jackson, R., 2000. The dynamics of fluidized particles. Cambridge.

Jiradilok, V., Gidaspow, D., Damronglerd, S., Koves, W.J., Mostofi, R., 2006. Kinetic theory based CFD simulation of turbulent fluidization of FCC particles in a riser. Chemical Engineering Science 61, 5544-5559.

Kanholy, S.K., Chodak, J., Lattimer, B.Y., Battaglia, F., 2012. Modeling and Predicting GasSolid Fluidized Bed Dynamics to Capture Nonuniform Inlet Conditions. ASME Journal of Fluids Engineering 134, 111303.

Krishna, R., Van Baten, J.M., 2001. Scaling up Bubble Column Reactors with the Aid of CFD. Chemical Engineering Research and Design 79, 283-309.

Lackermeier, U., Rudnick, C., Werther, J., Bredebusch, A., Burkhardt, H., 2001. Visualization of flow structures inside a circulating fluidized bed by means of laser sheet and image processing. Powder Technology 114, 71-83.

Lathouwers, D., Bellan, J., 2000. Modeling and simulation of bubbling fluidized beds containing particle mixtures. Proceedings of the Combustion Institute 28, 2297-2304.

Lettieri, P., Newton, D., Yates, J.G., 2002. Homogeneous bed expansion of FCC catalysts, influence of temperature on the parameters of the Richardson-Zaki equation. Powder Technology 123, 221-231. 
Liu, D.Y., Chen, X.P., Liang, C., Zhao, C.S., 2010. Solids Mixing in the Bottom Zone of Fluidized Beds, in: Yue, G., Zhang, H., Zhao, C., Luo, Z. (Eds.), Proceedings of the 20th International Conference on Fluidized Bed Combustion. Springer Berlin Heidelberg, pp. 459463.

Loezos, P.N., Costamagna, P., Sundaresan, S., 2002. The role of contact stresses and wall friction on fluidization. Chemical Engineering Science 57, 5123-5141.

Lu, B., Wang, W., Li, J., 2011. Eulerian simulation of gas-solid flows with particles of Geldart groups A, B and D using EMMS-based meso-scale model. Chemical Engineering Science 66, 4624-4635.

McKeen, T., Pugsley, T., 2003. Simulation and experimental validation of a freely bubbling bed of FCC catalyst. Powder Technology 129, 139-152.

Mostoufi, N., Chaouki, J., 2001. Local solid mixing in gas-solid fluidized beds. Powder Technology 114, 23-31.

Mostoufi, N., Chaouki, J., 2004. Flow structure of the solids in gas-solid fluidized beds. Chemical Engineering Science 59, 4217-4227.

Nguyen, H.V., Whitehead, A.B., Potter, O.E., 1977. Gas backmixing, solids movement, and bubble activities in large scale fluidized beds. AIChE Journal 23, 913-922.

Norouzi, H.R., Mostoufi, N., Mansourpour, Z., Sotudeh-Gharebagh, R., Chaouki, J., 2011. Characterization of solids mixing patterns in bubbling fluidized beds. Chemical Engineering Research and Design 89, 817-826.

Nyendu, G.C., 2015. Non-Catalytic Co-Gasification of Sub-Bituminous Coal and Biomass, Biological Engineering. Utah State University.

Parmentier, J.-F., Simonin, O., Delsart, O., 2008. A numerical study of fluidization behavior of Geldart B, A/B and A particles using an Eulerian multifluid modeling approach. Circulating Fluidized Bed Technology IX, Hamburg, Germany.

Patankar, S.V., 1980. Numerical heat transfer and fluid flow. CRC Press.

Prins, M.J., Ptasinski, K.J., Janssen, F.J.J.G., 2007. From coal to biomass gasification: Comparison of thermodynamic efficiency. Energy 32, 1248-1259.

Rapagna, S., Foscolo, P.U., Gibilaro, L.G., 1994. The influence of temperature on the quality of gas fluidization. International Journal of Multiphase Flow 20, 305-313.

Reddy, R.K., Joshi, J.B., 2010. CFD modeling of pressure drop and drag coefficient in fixed beds: Wall effects. Particuology 8, 37-43.

Rhodes, M.J., Wang, X.S., Nguyen, M., Stewart, P., Liffman, K., 2001. Study of mixing in gasfluidized beds using a DEM model. Chemical Engineering Science 56, 2859-2866. 
Rowe, P.N., and Nienow, A. W., and Agbim, A. J., 1972. A Preliminary Quantitative Study of Particle Segregation in Gas Fluidised Beds - Binary Systems of Near Spherical Particles. Transactions of the Institution of Chemical Engineers 50, 310.

Shuyan, W., Zhiheng, S., Huilin, L., Long, Y., Wentie, L., Yonlong, D., 2008. Numerical predictions of flow behavior and cluster size of particles in riser with particle rotation model and cluster-based approach. Chemical Engineering Science 63, 4116-4125.

Sidorenko, I., Rhodes, M.J., 2004. Influence of pressure on fluidization properties. Powder Technology 141, 137-154.

Simone, S., Harriott, P., 1980. Fluidization of fine powders with air in the particulate and the bubbling regions. Powder Technology 26, 161-167.

Srivastava, A., Sundaresan, S., 2002. Role of wall friction in fluidization and standpipe flow. Powder Technology 124, 45-54.

Stein, M., Ding, Y.L., Seville, J.P.K., Parker, D.J., 2000. Solids motion in bubbling gas fluidised beds. Chemical Engineering Science 55, 5291-5300.

Sun, J., Battaglia, F., 2006. Hydrodynamic modeling of particle rotation for segregation in bubbling gas-fluidized beds. Chemical Engineering Science 61, 1470-1479.

Syamlal, M., 1987. The particle-particle drag term in a multiparticle model of fluidization. National Technical Information Service, Springfield, VA.

Syamlal, M., 1997. Higher order discretization methods for the numerical simulation of fluidized beds. EG and G Technical Services of West Virginia, Inc., Morgantown, WV (United States).

Syamlal, M., 1998. MFIX documentation: Numerical technique. National Energy Technology Laboratory, Department of Energy, Technical Note No. DOE/MC31346-5824.

Syamlal, M., Rogers, W., O’Brien, T.J., 1993. MFIX documentation: Theory guide. National Energy Technology Laboratory, Department of Energy, Technical Note DOE/METC-95/1013 and NTIS/DE95000031.

Van Wachem, B.G.M., Schouten, J.C., van den Bleek, C.M., Krishna, R., Sinclair, J.L., 2001. Comparative analysis of CFD models of dense gas-solid systems. AIChE Journal 47, 1035-1051.

Wang, J., 2009. A Review of Eulerian Simulation of Geldart A Particles in Gas-Fluidized Beds. Industrial \& Engineering Chemistry Research 48, 5567-5577.

Wang, J., van der Hoef, M.A., Kuipers, J.A.M., 2010. CFD study of the minimum bubbling velocity of Geldart A particles in gas-fluidized beds. Chemical Engineering Science 65, 37723785.

Woollard, I.N.M., Potter, O., 1968. Solids mixing in fluidized beds. AIChE Journal 14, 388-391. 
Xie, H.Y., Geldart, D., 1995. Fluidization of FCC powders in the bubble-free regime: effect of types of gases and temperature. Powder Technology 82, 269-277.

Xie, N., Battaglia, F., Pannala, S., 2008. Effects of using two- versus three-dimensional computational modeling of fluidized beds: Part II, budget analysis. Powder Technology 182, 1424.

Ye, M., van der Hoef, M.A., Kuipers, J.A.M., 2004. A numerical study of fluidization behavior of Geldart A particles using a discrete particle model. Powder Technology 139, 129-139.

Ye, M., van der Hoef, M.A., Kuipers, J.A.M., 2005. The effects of particle and gas properties on the fluidization of Geldart A particles. Chemical Engineering Science 60, 4567-4580.

Ye, M., Wang, J., van der Hoef, M.A., Kuipers, J.A.M., 2008. Two-fluid modeling of Geldart A particles in gas-fluidized beds. Particuology 6, 540-548. 
Table 1. Summary of literature that employ Eulerian models

\begin{tabular}{|c|c|c|}
\hline Study & Methodology & Comments \\
\hline $\begin{array}{l}\text { Ferschneider and Mege (1996); } \\
\text { Krishna and Van Baten (2001); } \\
\text { Van Wachem et al. (2001) }\end{array}$ & $\begin{array}{l}\text { Showed that there are some } \\
\text { deficiencies in predicting Geldart } \\
\text { A fluidization behavior }\end{array}$ & $\begin{array}{l}\text { To overcome these deficiencies } \\
\text { and to capture fine particle } \\
\text { fluidization behavior many } \\
\text { attempts have been made. }\end{array}$ \\
\hline $\begin{array}{l}\text { (Harris et al., 2002; } \\
\text { Lackermeier et al., 2001; } \\
\text { Mostoufi and Chaouki, 2004)) }\end{array}$ & $\begin{array}{l}\text { Reported the existence of particle } \\
\text { clusters in gas-solids flows due to } \\
\text { inter-particles forces }\end{array}$ & $\begin{array}{l}\text { Particle clusters are the result of } \\
\text { inter-particles forces that are } \\
\text { specifically important for Geldart } \\
\text { A particles. }\end{array}$ \\
\hline $\begin{array}{l}\text { (Huilin et al., 2005; Shuyan et } \\
\text { al., 2008)) }\end{array}$ & $\begin{array}{l}\text { Proposed a cluster-based model } \\
\text { to represent the movement of } \\
\text { particle clusters }\end{array}$ & $\begin{array}{l}\text { Correctly predicting the size of } \\
\text { clusters for different applications } \\
\text { of the models is difficult. }\end{array}$ \\
\hline $\begin{array}{l}\text { (McKeen and Pugsley, 2003; } \\
\text { Ye et al., 2004; Ye et al., } \\
\text { 2008)) }\end{array}$ & $\begin{array}{l}\text { Modified the drag models to } \\
\text { capture the importance of particle } \\
\text { clusters in Geldart A fluidization } \\
\text { behavior }\end{array}$ & $\begin{array}{l}\text { Model uses a scaling factor that is } \\
\text { not general and must be } \\
\text { determined for each application. }\end{array}$ \\
\hline $\begin{array}{l}\text { Parmentier et al. (2008)); Wang } \\
\text { et al. (2009; 2010)) }\end{array}$ & $\begin{array}{l}\text { Investigated the influence of } \\
\text { mesh size on particle fluidization } \\
\text { and emphasized the necessity for } \\
\text { using a fine grid and small time } \\
\text { step }\end{array}$ & $\begin{array}{l}\text { With current and foreseeable } \\
\text { computer resources, their method } \\
\text { is very expensive if even feasible. }\end{array}$ \\
\hline $\begin{array}{l}\text { Wang (2009), Lu et al. (2011), } \\
\text { Benzarti et al. (2012) }\end{array}$ & $\begin{array}{l}\text { Employed new drag models to } \\
\text { account for the presence of } \\
\text { particle clusters over a wide } \\
\text { range of length and time scales }\end{array}$ & $\begin{array}{l}\text { Method incorporates kinetic theory } \\
\text { for granular flow, which assumes } \\
\text { homogeneous flow. }\end{array}$ \\
\hline
\end{tabular}


Table 2. Properties for coal, and poplar wood

\begin{tabular}{|l|c|c|}
\hline \multirow{2}{*}{ Property } & \multicolumn{2}{|c|}{ Material } \\
\cline { 2 - 3 } & Coal & Poplar \\
\hline $\bar{d}_{p}(\mu \mathrm{m})$ & 62 & 151 \\
\hline$\rho_{s}\left(\mathrm{~g} / \mathrm{cm}^{3}\right)$ & 1.38 & 0.4 \\
\hline$\rho_{b}\left(\mathrm{~g} / \mathrm{cm}^{3}\right)$ & 0.57 & 0.25 \\
\hline$\varepsilon_{m f}$ & 0.59 & 0.38 \\
\hline
\end{tabular}

Table 3. Grid resolution and central processing unit.

\begin{tabular}{|l|c|c|c|}
\hline Mesh & $\mathbf{2 0} \times \mathbf{1 0 0}$ & $\mathbf{4 0} \times \mathbf{2 0 0}$ & $\mathbf{8 0} \times \mathbf{4 0 0}$ \\
\hline \# Cells & 2000 & 8000 & 32000 \\
\hline Cell size $\left(\mathrm{cm}^{2}\right)$ & $0.254 \times 0.3$ & $0.127 \times 0.15$ & $0.0635 \times 0.075$ \\
\hline CPU $(\mathrm{s})$ & 2,270 & 15,611 & 107,966 \\
\hline
\end{tabular}

Table 4. Properties for binary mixture model

\begin{tabular}{|l|c|c|c|c|c|c|}
\hline \multirow{3}{*}{ Properties } & \multicolumn{6}{|c|}{ Mixtures } \\
\cline { 2 - 7 } & \multicolumn{2}{|c|}{$\mathbf{9 0 : 1 0}$} & \multicolumn{2}{c|}{$\mathbf{8 0 : 2 0}$} & \multicolumn{2}{c|}{$\mathbf{7 0 : 3 0}$} \\
\cline { 2 - 7 } & Coal & Poplar & Coal & Poplar & Coal & Poplar \\
\hline $\bar{d}_{p}(\mu \mathrm{m})$ & 62 & 151 & 62 & 151 & 62 & 151 \\
\hline$\rho_{s}\left(\mathrm{~g} / \mathrm{cm}^{3}\right)$ & 1.38 & 0.4 & 1.38 & 0.4 & 1.38 & 0.4 \\
\hline$\rho_{b}\left(\mathrm{~g} / \mathrm{cm}^{3}\right)$ & \multicolumn{3}{|c|}{0.57} & \multicolumn{2}{c|}{0.48} & \multicolumn{2}{c|}{0.43} \\
\hline$X_{i}$ & 0.9 & 0.1 & 0.8 & 0.2 & 0.7 & 0.3 \\
\hline$\varepsilon_{m f}$ & \multicolumn{3}{|c|}{0.49} & \multicolumn{2}{c|}{0.48} & \multicolumn{2}{c|}{0.45} \\
\hline
\end{tabular}




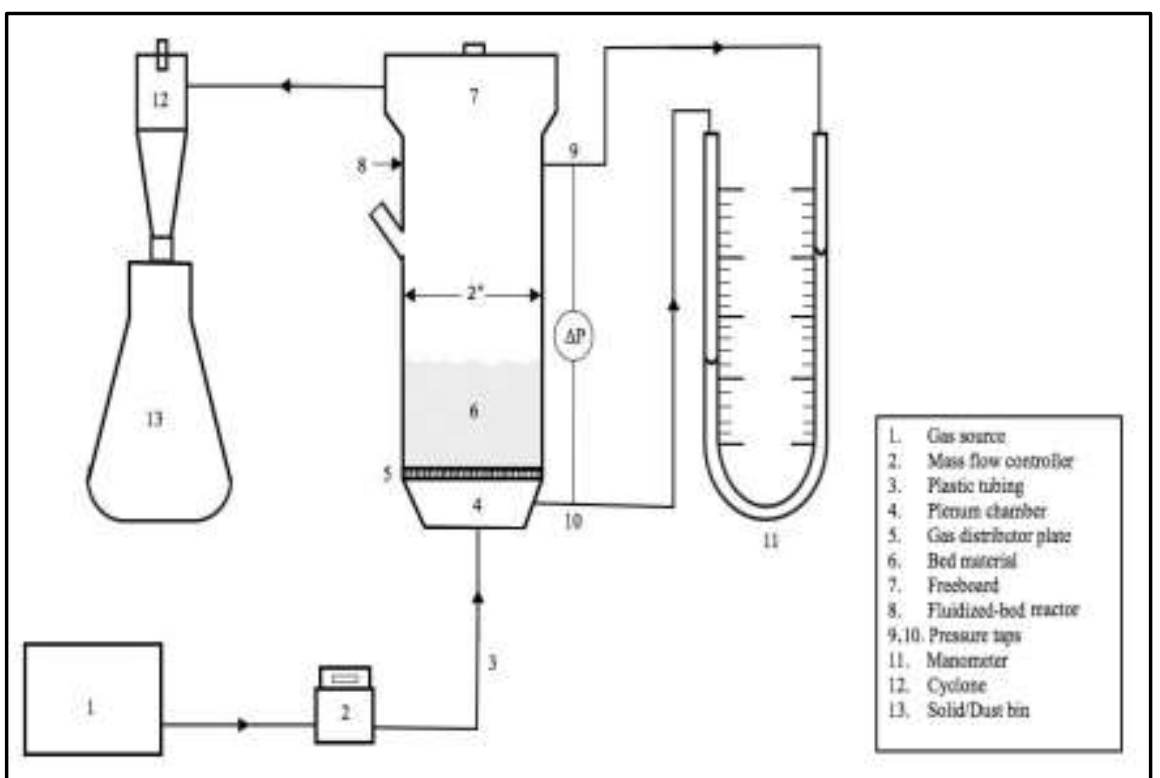

(a)

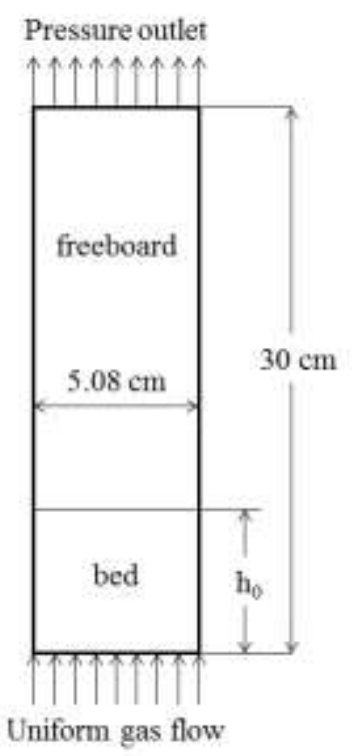

(b)

Figure 1. (a) Schematic diagram of experimental setup, and (b) the 2D plane representing the chamber of the cylindrical reactor 


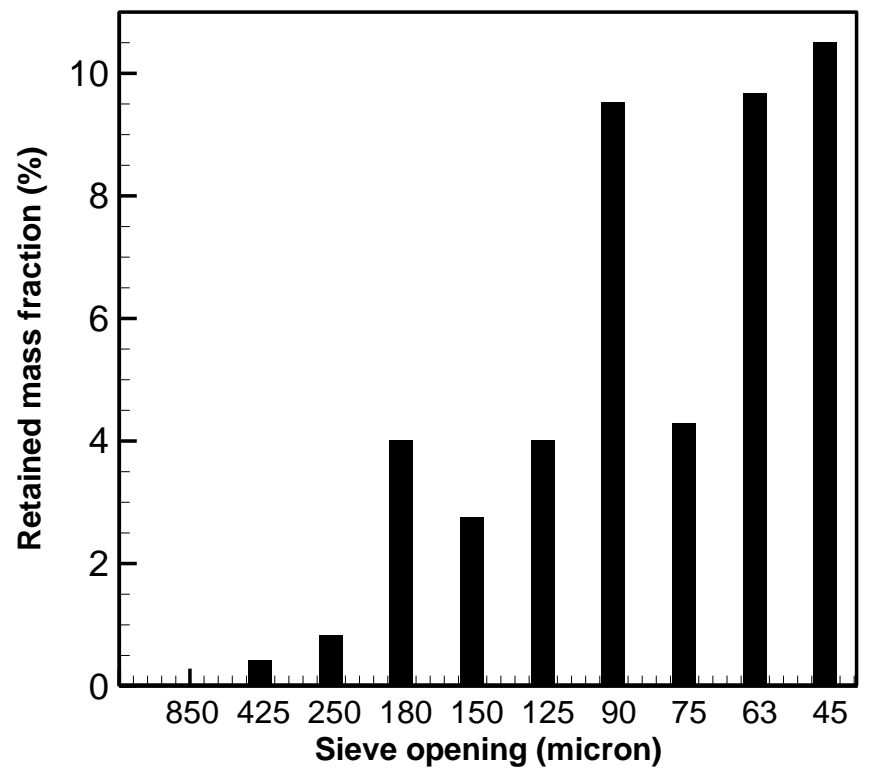

Figure 2. The particle size distribution for coal. 


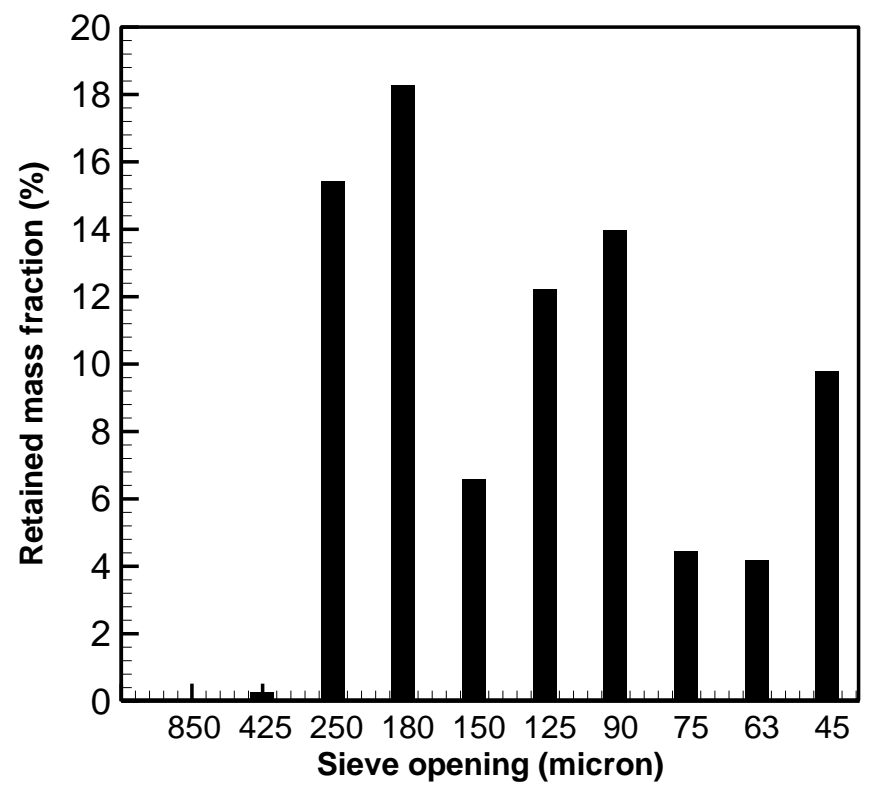

Figure 3. The particle size distribution for poplar wood. 


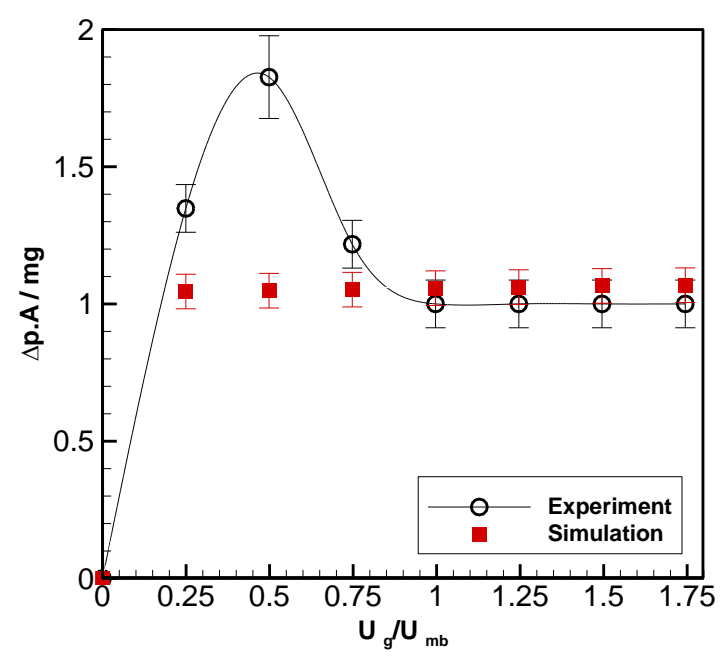

(a)

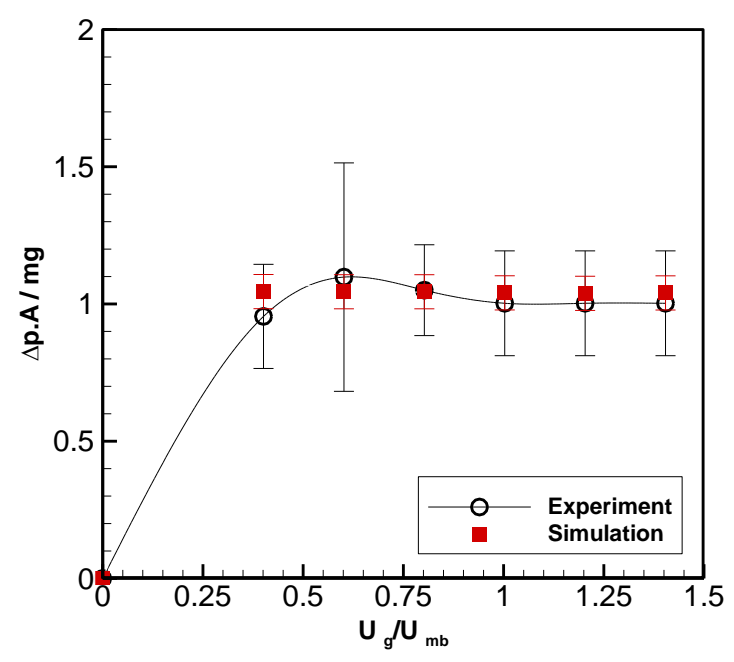

(b)

Figure 4. Pressure drop versus the gas inlet velocity comparing experiments and simulations for $(a)$ coal $\left(U_{m b}=6.6 \mathrm{~m} / \mathrm{s}\right),(b) \operatorname{poplar} \operatorname{wood}\left(U_{m b}=8.2 \mathrm{~m} / \mathrm{s}\right)$. 


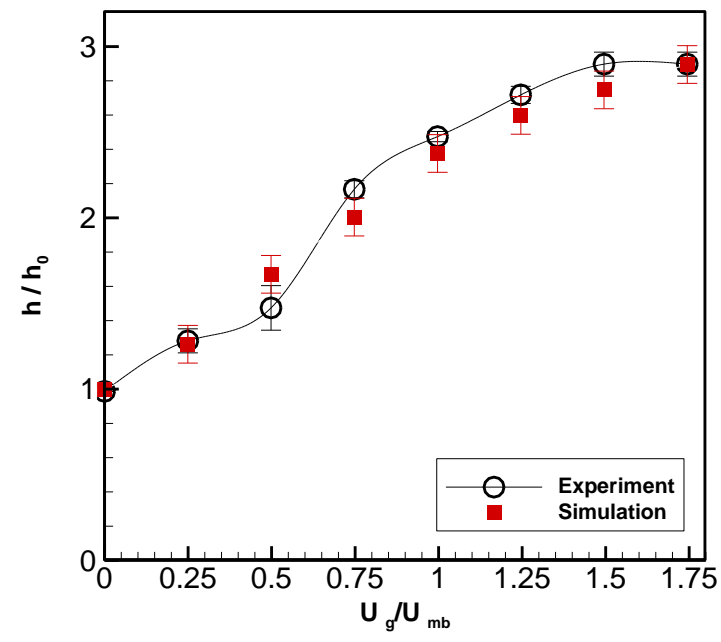

(a)

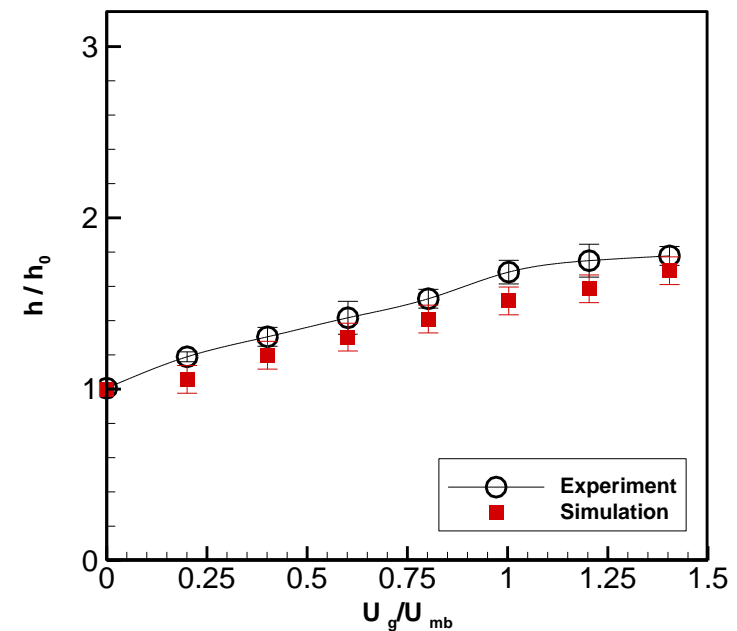

(b)

Figure 5. Bed height for different gas inlet velocities comparing experiments and simulations for (a) coal $\left(U_{m b}=6.6 \mathrm{~m} / \mathrm{s}\right)$ and $(b) \operatorname{poplar} \operatorname{wood}\left(U_{m b}=8.2 \mathrm{~m} / \mathrm{s}\right)$. 


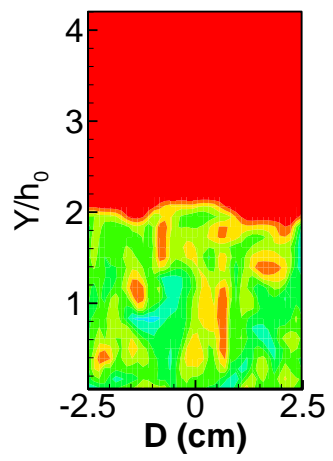

(a)

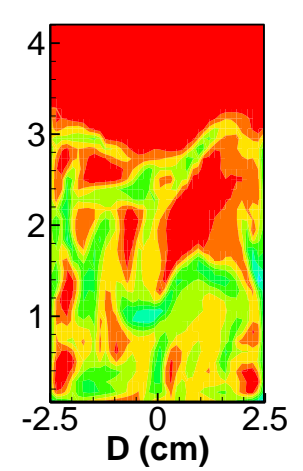

(b)

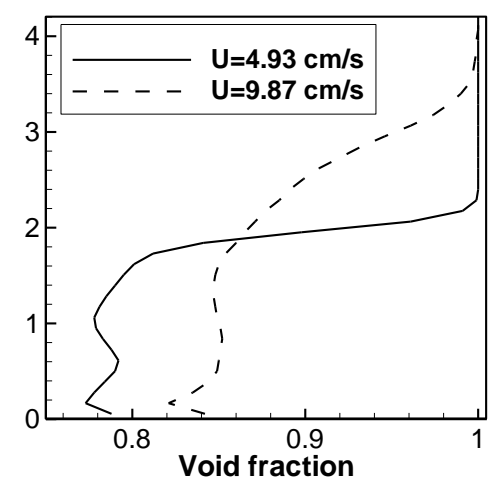

(c)

Figure 6. Instantaneous void fraction contours at $t=30 \mathrm{~s}$ for coal at (a) $U_{g}=\mathbf{4 . 9 3} \mathbf{c m} / \mathrm{s}$ and (b) $U_{g}=9.87 \mathrm{~cm} / \mathrm{s}$; and (c) void fraction horizontally averaged across the reactor diameter versus axial direction. 


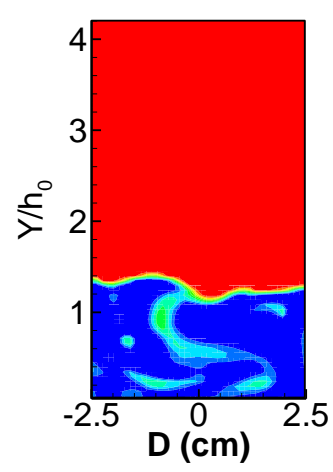

(a)

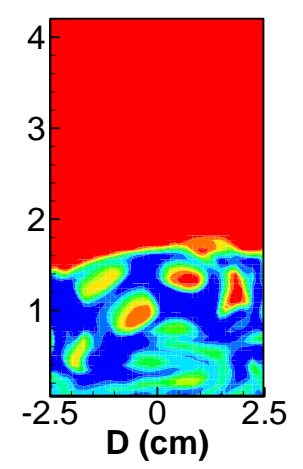

(b)

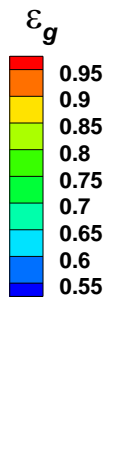

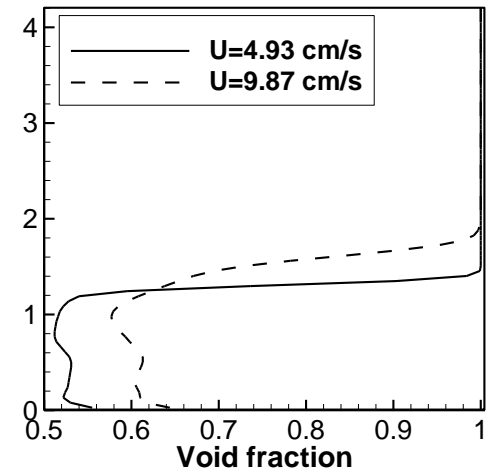

(c)

Figure 7. Instantaneous void fraction contours at $\mathbf{t}=\mathbf{3 0} \mathrm{s}$ for poplar wood at (a) $U_{g}=\mathbf{4 . 9 3}$ $\mathbf{c m} / \mathrm{s}$ and $(\mathbf{b}) U_{g}=9.87 \mathrm{~cm} / \mathrm{s}$; and (c) void fraction horizontally averaged across the reactor diameter versus axial direction. 


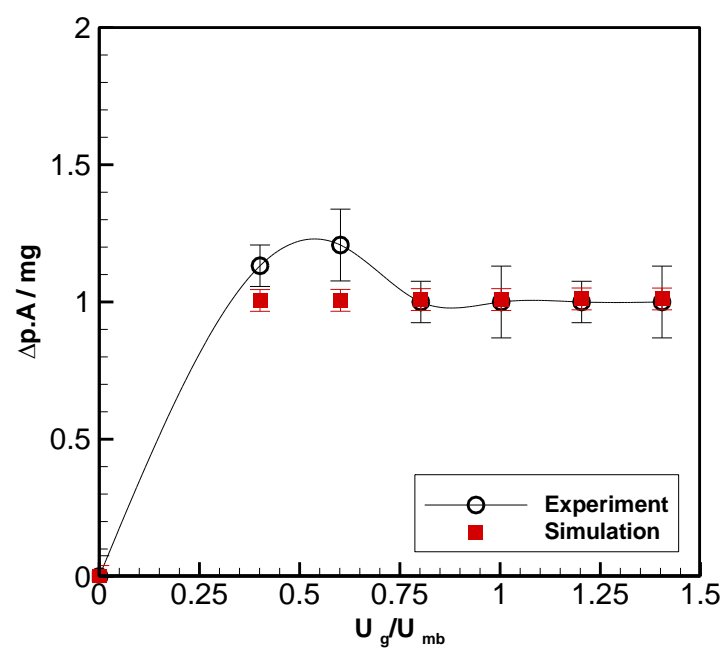

(a)

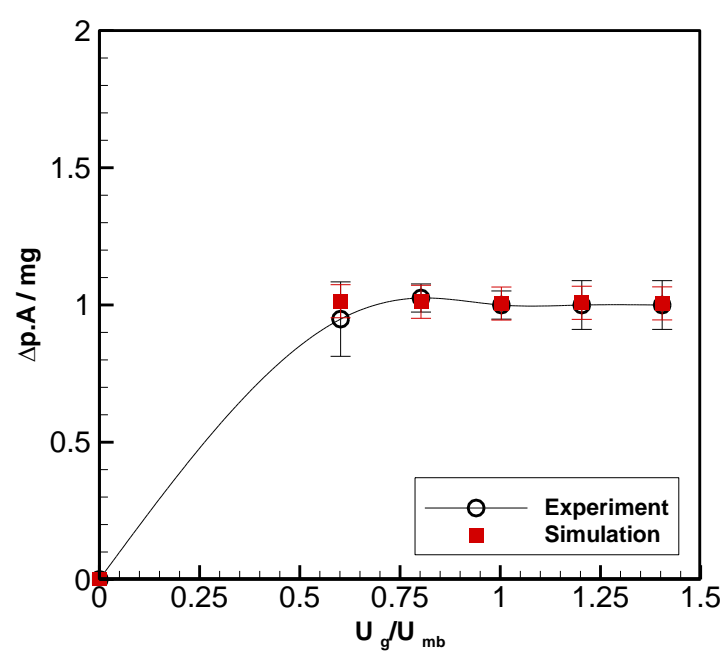

(b)

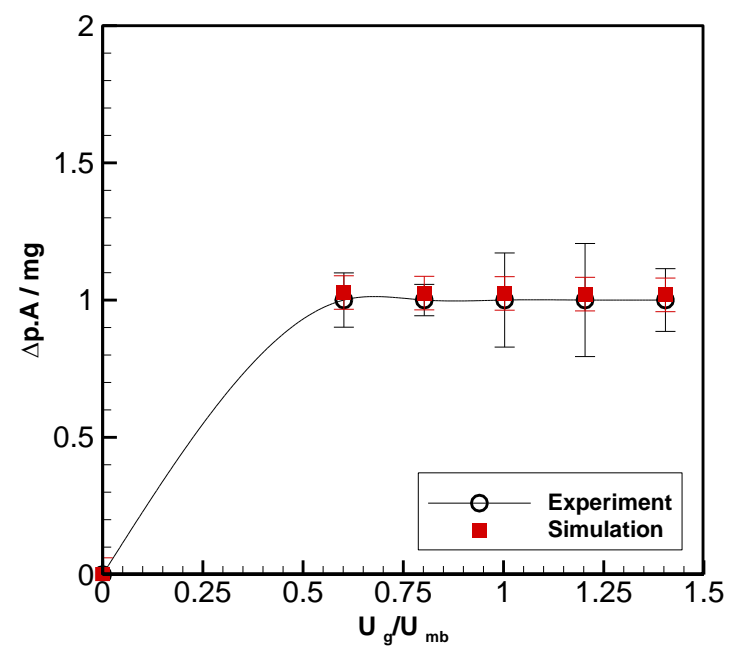

(c)

Figure 8. Pressure drop versus the gas inlet velocity comparing experiments and simulations for mass ratios for (a) 90:10 $\left(U_{\mathrm{mb}}=8.2 \mathrm{~m} / \mathrm{s}\right)$, (b) 80:20 $\left(\mathrm{U}_{\mathrm{mb}}=8.2 \mathrm{~m} / \mathrm{s}\right)$ and (c) 70:30 $\left(U_{m b}=8.2 \mathrm{~m} / \mathrm{s}\right)$ mass ratio of coal-poplar wood. 


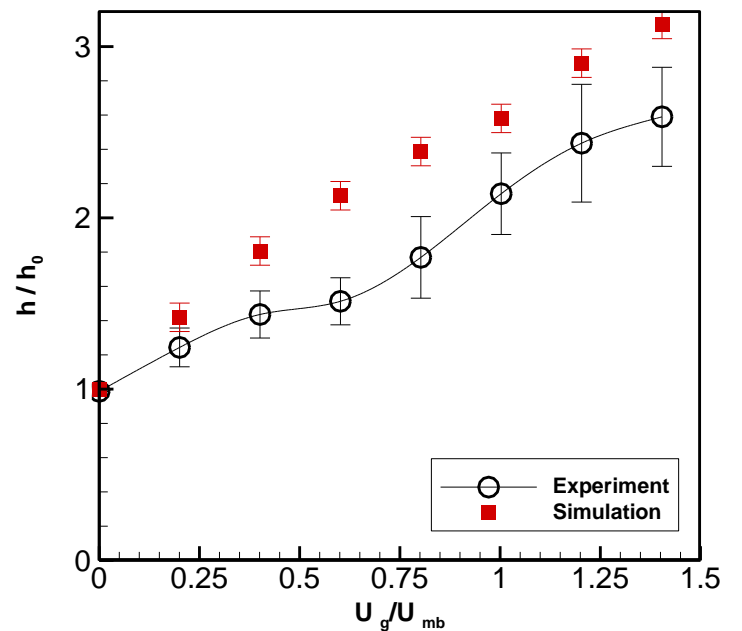

(a)

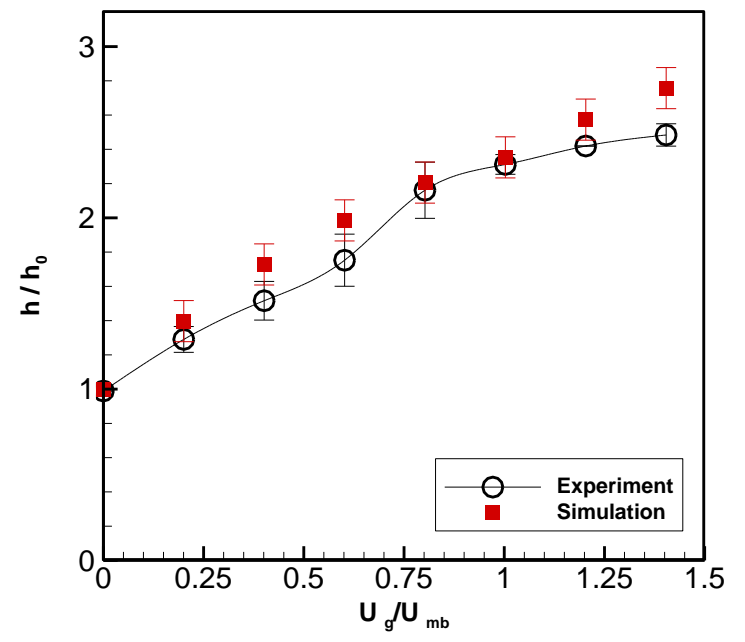

(b)

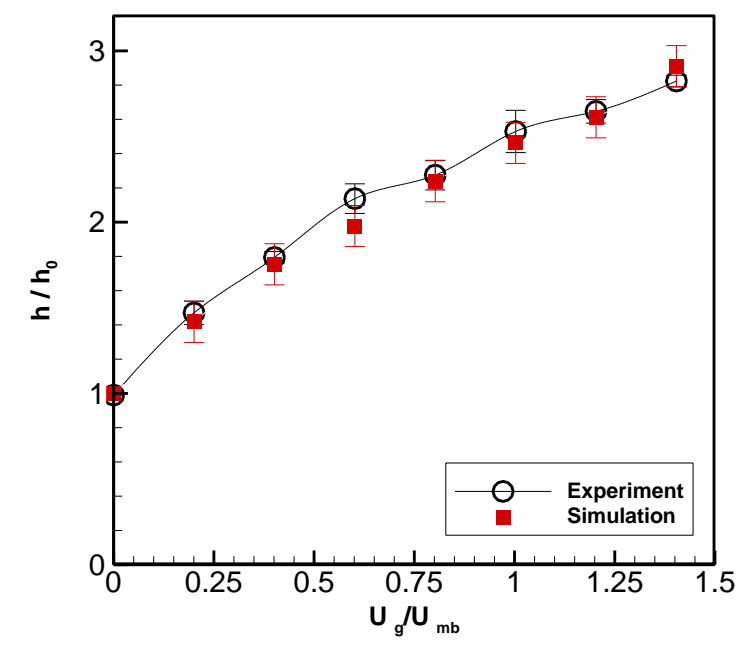

(c)

Figure 9. Bed height for different gas inlet velocities comparing experiments and simulations for mass ratios for (a) 90:10, (b) 80:20 and (c) 70:30 mass ratio of coal-poplar wood. 


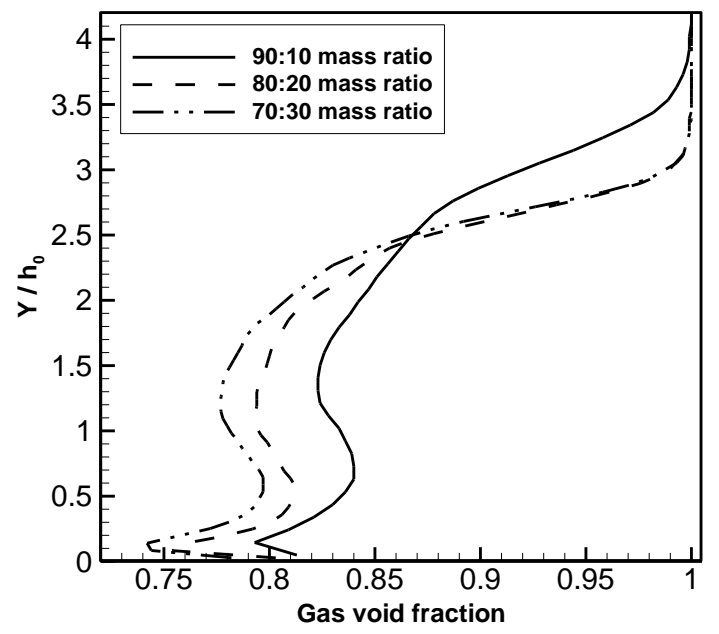

(a)

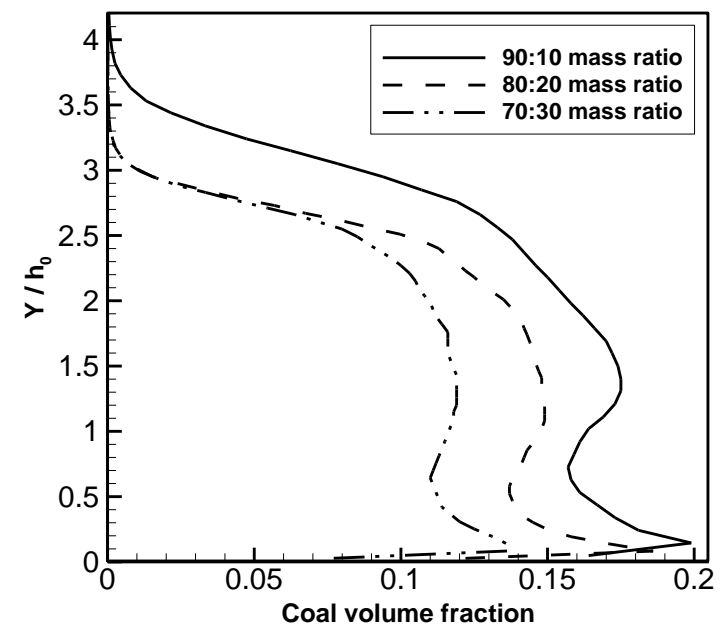

(b)

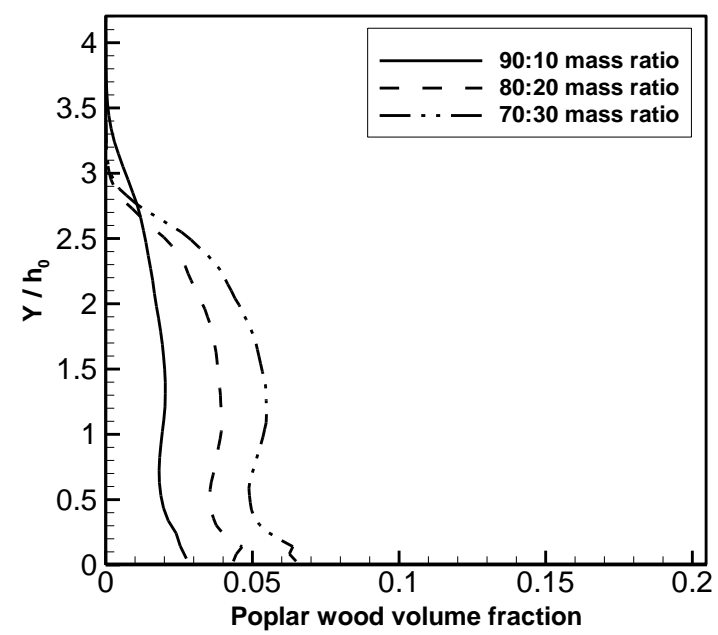

(c)

Figure 10. Volume fraction horizontally averaged across the reactor diameter versus axial direction for $U_{g}=9.87 \mathrm{~cm} / \mathrm{s}$ with 90:10, 80:20 and 70:30 mass ratio of coal-poplar wood for (a) gas, (b) coal and (c) poplar wood. 


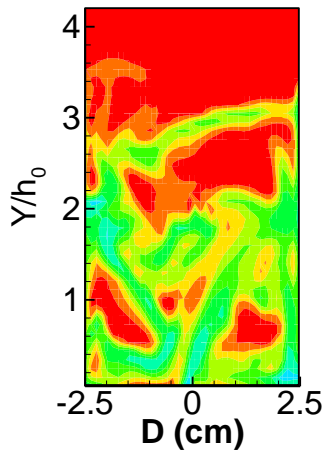

90:10 mass ratio

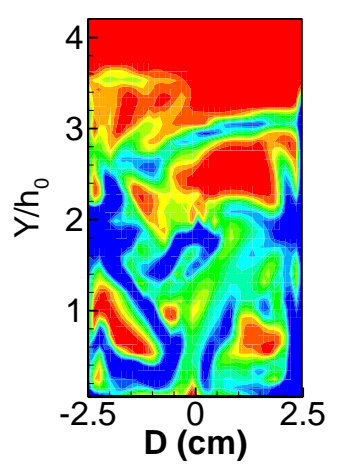

90:10 mass ratio

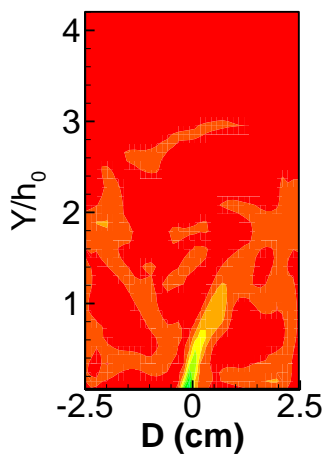

90:10 mass ratio

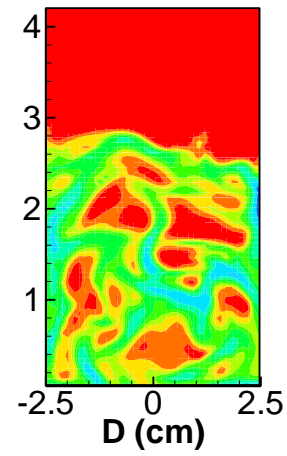

80:20 mass ratio

(a)

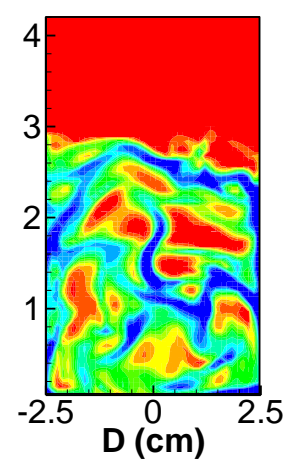

80:20 mass ratio

(b)

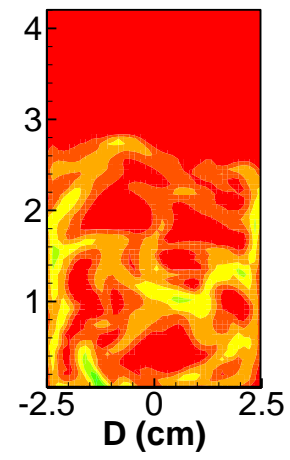

80:20 mass ratio

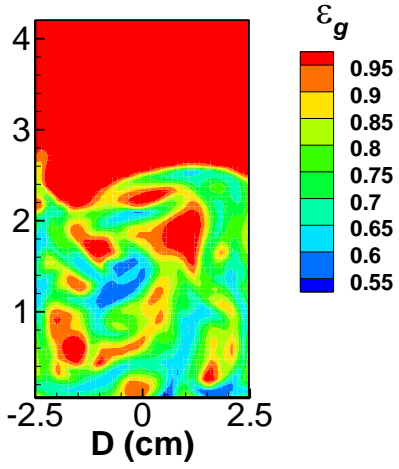

70:30 mass ratio

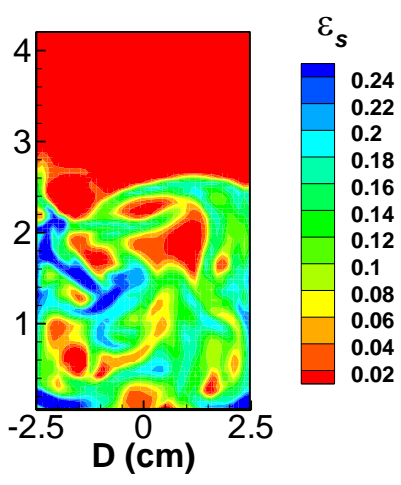

70:30 mass ratio

(c)

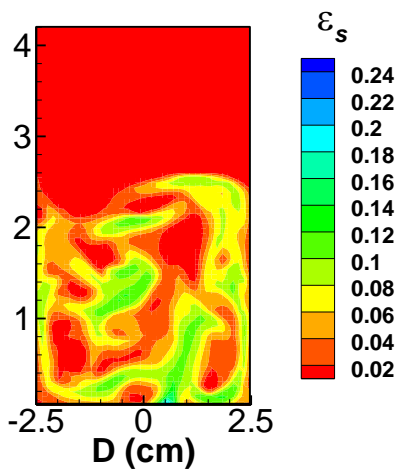

70:30 mass ratio

Figure 11. Instantaneous volume fraction contours for all mass ratios of coal-poplar wood at $U_{g}=9.87 \mathrm{~cm} / \mathrm{s}$ for (a) gas, (b) coal and (c) poplar-wood. 


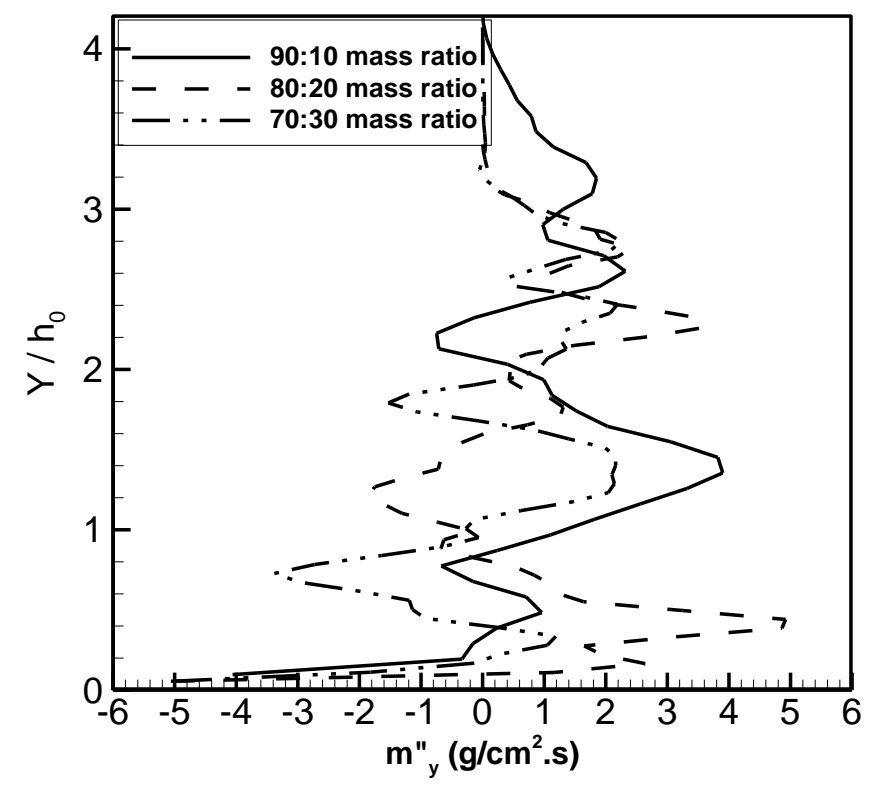

(a)

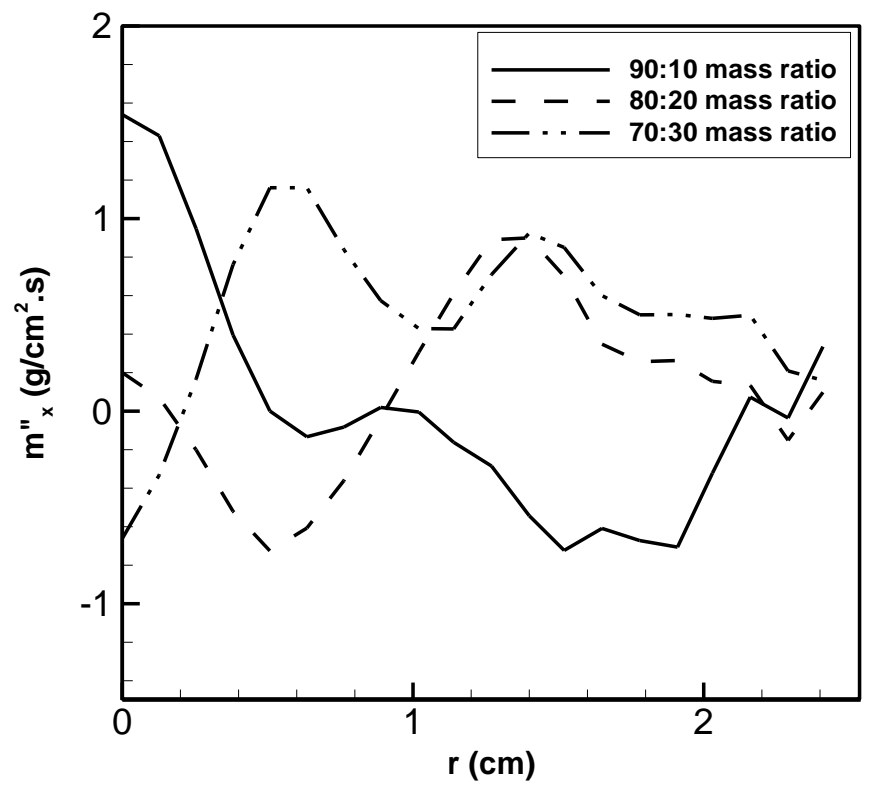

(b)

Figure 12. Time-averaged a) axial solids mass flux spatially averaged across the bed width versus the nondimensional height and $b$ ) lateral solids mass flux vertically averaged across the bed height versus the radius of the reactor, for $U_{g}=9.87 \mathrm{~cm} / \mathrm{s}$ 

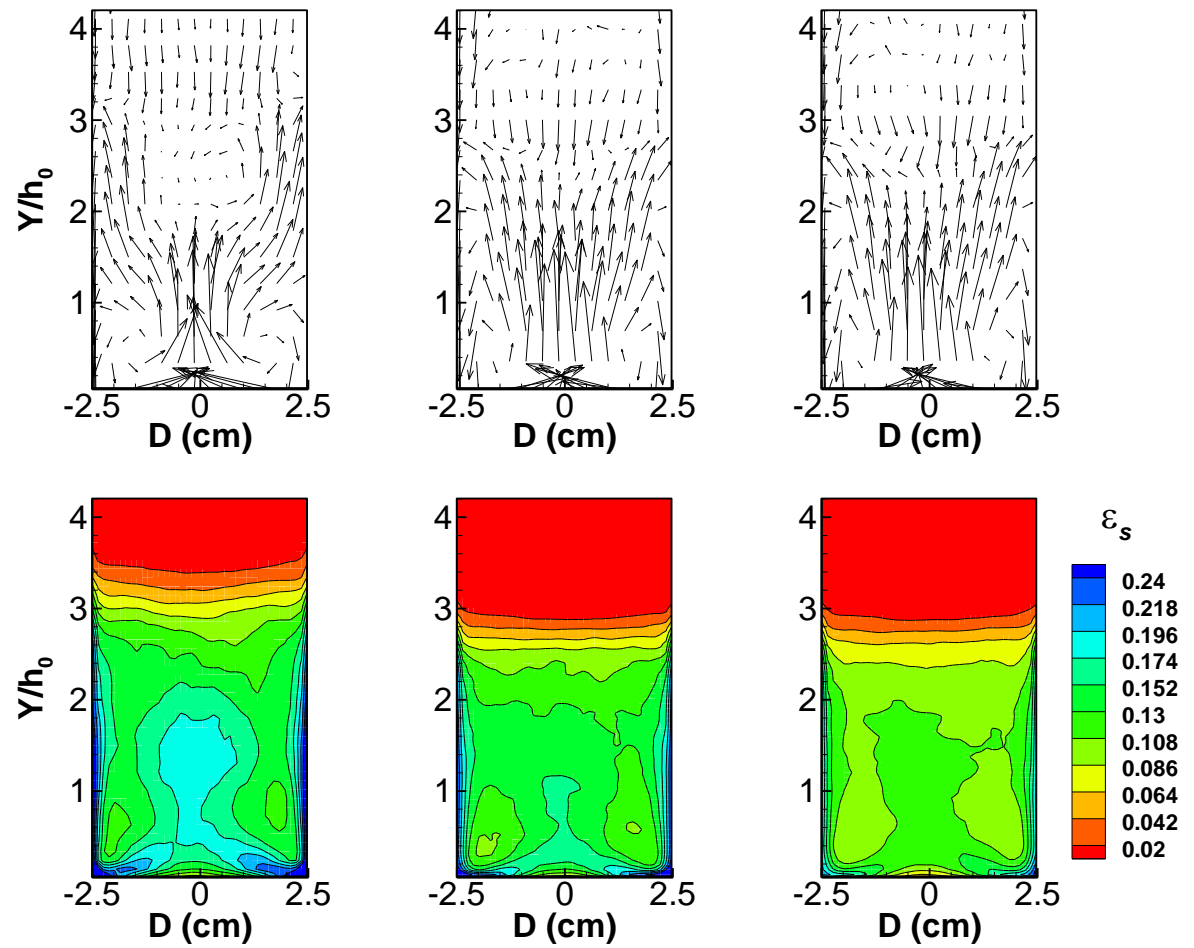

(a)

(b)

(c)

Figure 13. Time-average coal velocity vectors for $U_{g}=9.87 \mathrm{~cm} / \mathrm{s}$ for (a) $90: 10$, (b) 80:20, (c) 70:30 mass ratio of coal-poplar wood. 


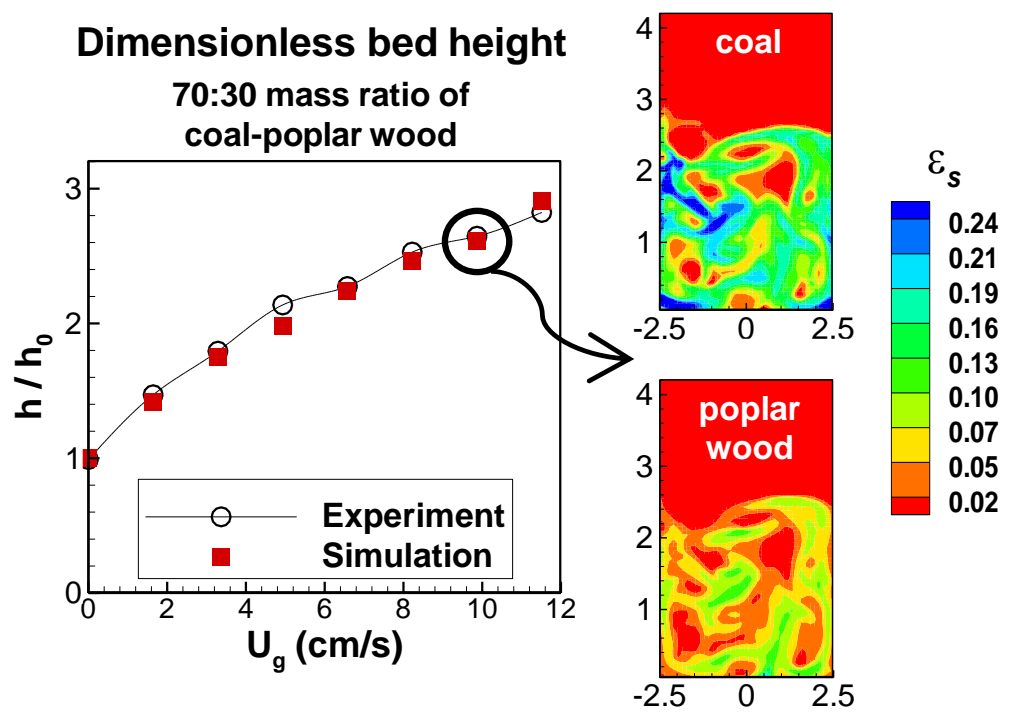

